\title{
Long-term outcomes of frozen elephant trunk for type A aortic dissection in patients with Marfan syndrome
}

\author{
Wei-Guo Ma, MD, PhD, ${ }^{\text {a,b,c }}$ Wei Zhang, MD, ${ }^{a}$ Jun-Ming Zhu, MD, ${ }^{\text {a,b }}$ Bulat A. Ziganshin, MD, \\ Ai-Hua Zhi, MD, ${ }^{b}$ Jun Zheng, MD, PhD, ${ }^{a, b}$ Yong-Min Liu, MD, ${ }^{\mathrm{a}, \mathrm{b}}$ John A. Elefteriades, MD, ${ }^{\mathrm{c}}$ and \\ Li-Zhong Sun, MD ${ }^{a, b}$
}

\section{ABSTRACT}

Objective: The use of the frozen elephant trunk (FET) technique for repair of type A aortic dissection (TAAD) in Marfan syndrome (MFS) is controversial. We seek to evaluate the efficacy of FET and total arch replacement (TAR) for TAAD in patients with MFS.

Methods: The early and long-term outcomes were analyzed for 106 patients with MFS (mean age, $34.5 \pm 9.7$ years) undergoing FET + TAR for TAAD.

Results: Operative mortality was $6.6 \%$ (7 of 106). Spinal cord injury and stroke occurred in 1 patient each $(0.9 \%)$, and reexploration for bleeding occurred in 6 patients $(5.7 \%)$. Extra-anatomic bypass was the sole risk factor for operative mortality and morbidity (odds ratio [OR], 7.120; 95\% confidence interval [CI], $1.018-49.790 ; P=.048$ ). Follow-up was complete in $97.0 \%$ (96 of 99), averaging $6.3 \pm 2.8$ years. Late death occurred in 17 patients. Patients with acute TAAD were less prone to late death than those with chronic TAAD (OR, 0.112; 95\% CI, 0.021-0.587; $P=.048$ ). Twelve patients required late reoperation, including thoracoabdominal aortic repair in 8 , thoracic endovascular aortic repair for distal new entry in 3, and coronary anastomotic repair in 1 . At 5 years, survival was $86.6 \%(95 \% \mathrm{CI}, 77.9 \%-92.0 \%)$ and freedom from reoperation was $88.8 \%$ $(95 \% \mathrm{CI}, 80.1 \%-93.4 \%)$, and at 8 years, survival was $74.1 \%(95 \% \mathrm{CI}$, $61.9 \%-83.0 \%)$ and freedom from reoperation was $84.2 \%(95 \% \mathrm{CI}, 72.4 \%$ $91.2 \%$ ). In competing risks analysis, mortality was $4 \%$ at 5 years, $18 \%$ at 8 years, and $25 \%$ at 10 years; the respective rates of reoperation were $10 \%, 15 \%$, and $15 \%$; and the respective rates of survival without reoperation were $86 \%, 67 \%$, and $60 \%$. Survival was significantly higher in patients who underwent root procedures during FET + TAR $(P=.047)$. Risk factors for reoperation were days from diagnosis to surgery (OR, 1.160; 95\% CI, 1.043-1.289; $P=.006)$ and Bentall procedure (OR, 12.012; 95\% CI, 1.041-138.606; $P=.046)$.

Conclusions: The frozen elephant trunk and total arch replacement procedure can be safely performed for TAAD in MFS with low operative mortality, favorable long-term survival and freedom from reoperation. A concomitant Bentall procedure was predictive of better long-term survival and increased risk for late reoperation. These results argue favorably for the use of the FET + TAR technique in the management of TAAD in patients with MFS. (J Thorac Cardiovasc Surg 2017;154:1175-89)

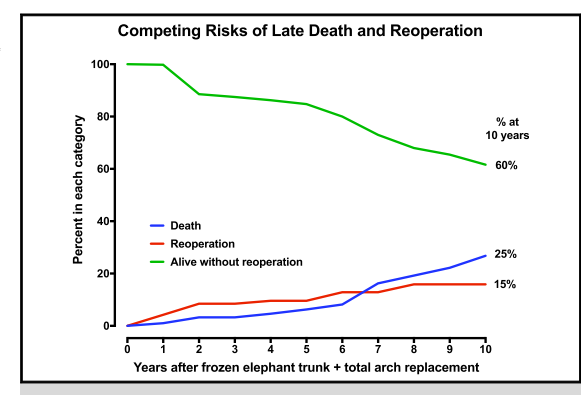

Incidences of reoperation, death, and event-free survival were $15 \%, 25 \%$ and $60 \%$, respectively, at 10 years.

\section{Central Message}

In 106 Marfan syndrome patients with type $\mathrm{A}$ aortic dissection, the frozen elephant trunk and total arch replacement technique has achieved low operative mortality, favorable long-term survival and freedom from reoperation

\section{Perspective}

The extent of surgical repair and the use of the frozen elephant trunk (FET) technique are controversial for type A dissection in Marfan syndrome. This study found favorable early and long-term results via total arch replacement with FET. A Bentall procedure during FET was predictive of better late survival and increased risk for reoperation. This extensive surgical approach is recommended in such a setting.

See Editorial Commentary page 1190.

See Editorial page 1169.

\footnotetext{
From the ${ }^{a}$ Department of Cardiovascular Surgery, Beijing Aortic Disease Center, Beijing Anzhen Hospital of Capital Medical University, Beijing Institute of Heart, Lung and Blood Vessel Diseases, and Beijing Engineering Research Center of Vascular Prostheses; ${ }^{\mathrm{b}} \mathrm{Fu}$ Wai Hospital and Cardiovascular Institute, Chinese Academy of Medical Sciences, Beijing, China; and ${ }^{\mathrm{c}}$ Aortic Institute at Yale-New Haven, Yale University School of Medicine, New Haven, Conn.

This study was supported in part by National Key Technologies Research and Development Program (2015BA112B03) and Special Research Fund for Public Health and Welfare (201402009).

Drs Ma and Zhang contributed equally to this work.
}

Read at the 96th Annual Meeting of The American Association for Thoracic Surgery, Baltimore, Maryland, May 14-18, 2016.

Received for publication May 31, 2016; revisions received March 20, 2017; accepted for publication April 4, 2017; available ahead of print Aug 7, 2017.

Address for reprints: Li-Zhong Sun, MD, Department of Cardiovascular Surgery, Beijing Anzhen Hospital of Capital Medical University, 2 Anzhen Rd, Beijing 100029, China (E-mail: lizhongsun@outlook.com). $0022-5223 / \$ 36.00$

Copyright (c) 2017 by The American Association for Thoracic Surgery http://dx.doi.org/10.1016/j.jtcvs.2017.04.088 


\section{Abbreviations and Acronyms \\ $\mathrm{CI} \quad=$ confidence interval \\ $\mathrm{CPB}=$ cardiopulmonary bypass \\ $\mathrm{CT}=$ computed tomography \\ FET = frozen elephant trunk \\ MFS = Marfan syndrome \\ $\mathrm{OR} \quad=$ odds ratio}

PHACP $=$ previous history of aortic/cardiac surgical/endovascular procedure

TAAD $=$ type A aortic dissection

TAR $=$ total arch replacement

TEVAR $=$ thoracic endovascular aortic repair

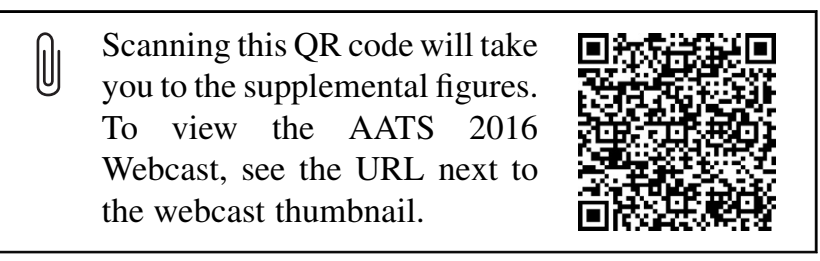

Marfan syndrome (MFS) is an autosomal dominant connective tissue disorder attributed to abnormal fibrillin1 caused by mutations in the fibrillin- 1 gene $(F B N 1)$ and dysregulation of transforming growth factor- $\beta$ activation and signaling. ${ }^{1}$ MFS affects approximately 1 in 3000 to 5000 individuals, and patients with MFS are highly predisposed to thoracic aortic aneurysm and/or dissection. ${ }^{2}$ The 2010 American Heart Association guidelines recommend prophylactic ascending aortic repair at a threshold of $5.0 \mathrm{~cm}$ to prevent catastrophic aortic events. ${ }^{3}$

Aortic dissection may result from a known thoracic aortic aneurysm or represent the initial presentation, and remains the most lethal complication of MFS. ${ }^{4}$ Even though one-third of patients with MFS will present with an aortic dissection, ${ }^{5}$ little data exist on the long-term outcomes and implications of surgical aortic dissection repair. ${ }^{4-11}$ Although excellent long-term outcomes have been achieved with aortic root operations, ${ }^{12,13}$ whether total arch replacement (TAR) is advisable at the time of root surgery remains controversial. ${ }^{5,14,15}$ Reports of reinterventions in MFS patients specify that distal aortic reoperations are more common among patients with type A aortic dissection (TAAD), ${ }^{16,17}$ and that TAR with an elephant trunk technique should be considered in such a setting. ${ }^{14,16}$

More recently, the morbidity associated with descending thoracic and thoracoabdominal aortic aneurysm disease as a late sequela of TAAD is driving the application of the "stent graft" technique, ${ }^{18}$ despite the consensus opinion that endovascular stent grafts should not be used in patients with connective tissue disorders. ${ }^{19}$ Since April 2003, ${ }^{7,8}$ our team has performed frozen elephant trunk (FET) and TAR using a 4- branched graft (ie, the Sun procedure ${ }^{20}$ ) in 106 consecutive patients with MFS. To date, there has been limited longterm follow-up data of patients with MFS undergoing FET + TAR for TAAD. Because the debate on the use of FET + TAR in MFS remains unsettled, we reviewed our early and long-term outcomes in these patients over a 12year period. This study aimed to evaluate the efficacy of the FET + TAR technique in the management of TAAD in MFS, and to address the question whether an extensive approach at the initial operation is associated with improved long-term outcomes.

\section{METHODS}

The Ethics Committees of Fu Wai Hospital and Cardiovascular Institute and Beijing Anzhen Hospital, Capital Medical University approved this retrospective study.

\section{Patients}

Between April 2003 and August 2013, our team operated on 421 patients with MFS and thoracic aortic disease. In all patients, the diagnosis of Marfan syndrome was confirmed preoperatively according to the Ghent criteria $^{21}$ and/or revised Ghent criteria ${ }^{22}$ based on physical examination findings. Among the 421 patients, 106 patients underwent FET + TAR for TAAD involving the arch and/or descending aorta (Figure 1). The mean patient age was $34.5 \pm 9.7$ years (range, 17-65 years), and 80 were male $(75.5 \%)$. Based on the interval from symptom onset to surgery, TAAD was acute $(\leq 14$ days) in 40 patients $(37.7 \%)$ and chronic (>14 days) in 66 patients $(62.3 \%)$. In patients with chronic type A aortic dissection, the mean intervals were 279.5 days (median, 62.6 days; interquartile range, 30.5-318.3 days) from symptom onset to surgery and $10.9 \pm 9.1$ days (median, 7.9 days) from diagnosis to surgery. Aortic regurgitation was present in 68 patients $(64.2 \%)$, hypertension in 35 $(33.0 \%)$, and malperfusion syndrome in $4(3.8 \%)$. The maximal ascending aortic diameter averaged $60.5 \pm 13.2 \mathrm{~mm}$ and did not differ significantly between the acute and chronic groups $(P=.067)$ (Table 1$)$.

Of note, 23 patients $(21.7 \%)$ had a previous history of aortic/cardiac surgical or endovascular procedure (PHACP), including composite aortic root replacement (Bentall) in 16 patients $(15.1 \%)$, ascending aortic replacement in $2(1.9 \%)$, thoracic endovascular aortic repair (TEVAR) in $2(1.9 \%)$, aortic root wrapping in $1(0.9 \%)$, hemiarch repair in $1(0.9 \%)$, mitral valve surgery in $2(1.9 \%)$, and coronary artery bypass grafting for dissected coronary artery in $1(0.9 \%)$. One patient with a previous Bentall procedure underwent reoperation for a residual dissection. The interval between the previous cardiovascular surgery and the index operation was $5.7 \pm 4.4$ years (range, 0.3-19.1 years).

\section{Indications for Surgery}

At our institution, TAAD in MFS is considered an indication for FET + TAR, as described previously. ${ }^{20}$ Specifically, in patients with MFS, we would perform FET + TAR for TAADs involving the ascending aorta, arch, and descending aorta (ie, DeBakey type I dissection) and TAADs confined to the ascending aorta (ie, DeBakey type II dissection), but with an enlarged proximal descending aorta $\geq 40 \mathrm{~mm}$ in diameter.

For MFS patients with TAAD that is confined to the ascending aorta, an ascending aortic replacement would be performed if the arch and descending aorta are intact; or an ascending aortic and hemiarch replacement performed if the proximal arch is involved. For critically ill MFS patients who have the surgical indications for FET + TAR but are hemodynamically unstable or with morbid types of malperfusion, we would prefer performing a limited repair (composite graft root or ascending aortic replacement), due to the guarded prognosis of this subgroup of patients. 


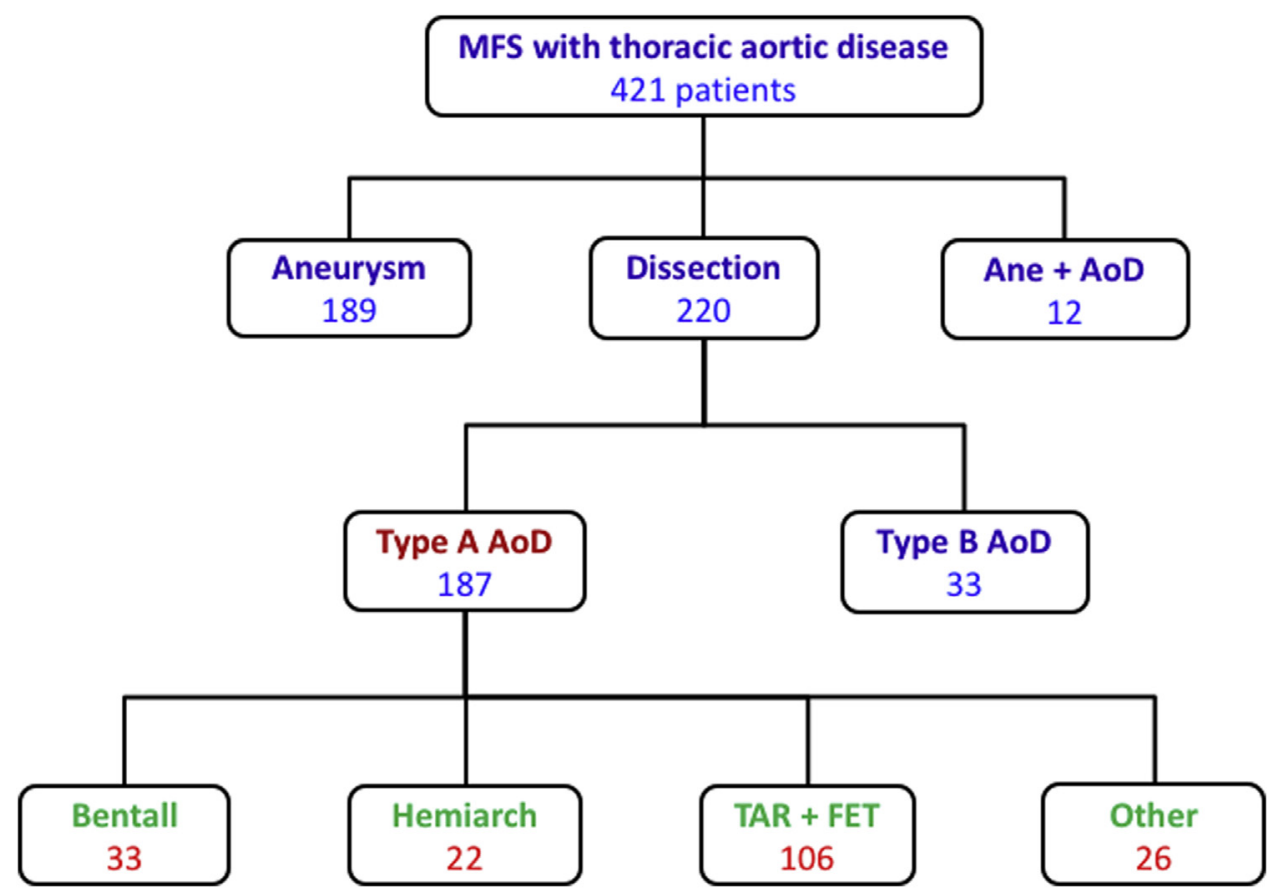

FIGURE 1. Patients with MFS and thoracic aortic disease. MFS, Marfan syndrome; Ane, aortic aneurysm; AoD, aortic dissection; TAR, total arch replacement; FET, frozen elephant trunk.

\section{Surgical Techniques}

The surgical technique has been previously described in detail. ${ }^{23,24}$ In brief, right axillary artery cannulation is used for cardiopulmonary bypass (CPB) and unilateral selective antegrade cerebral perfusion under moderate hypothermic circulatory arrest at $25^{\circ} \mathrm{C}$. The procedure involves deployment of an FET (Cronus; MicroPort Medical, Shanghai, China) in the descending aorta, followed by total arch replacement with a 4branched vascular graft (Maquet Cardiovascular, Wayne, NJ). To minimize the times of cerebral, myocardial, and spinal cord ischemia, distal reperfusion is initiated once the distal anastomosis is completed, and the left carotid artery is reconstructed first (after which rewarming is started and the brain is perfused bilaterally), followed by the ascending aorta (to resume myocardial perfusion), then the left subclavian artery, and finally the innominate artery. Aortic valve or root procedures and concomitant operations are performed during the cooling phase. Near-infrared spectroscopy and bispectral index are routinely used for neuromonitoring.

\section{Patient Follow-up}

All operative survivors were followed up regularly through clinic visits, phone calls, emails or letters. Patients were recommended to have computed tomography (CT) scan annually to detect endoleak, thrombosis and obliteration of the false lumen, residual intimal tear or distal new entry, aneurysmal dilatation in the distal aortic segments, and other complications.

By April 2016, clinical follow-up was complete in 96 of 99 operative survivors $(97.0 \%)$ averaging $6.3 \pm 2.8$ years (median, 6.4 years; range 0.3-12.0 years); a follow-up CT report or scan was available in 93 patients $(93.9 \%)$. The mean duration of radiologic follow-up was $3.5 \pm 2.5$ years (range, 0.3-10.2 years).

\section{Statistical Analysis}

The data were analyzed using the SPSS for Windows version 16.0 (SPSS Inc, Chicago, Ill). Data are expressed as mean \pm standard deviation or number (percentage) and were compared using the Student $t$ test or Pearson $\chi^{2}$ test for normally distributed data, and the Mann-Whitney $U$ test for nonnormally distributed data. Risk factors for early and late mortality, morbidity, and reinterventions were identified with univariate and multivariate analysis. Survival and freedom from reoperation were estimated using the KaplanMeier method, and intergroup comparisons were made with the log-rank test. Competing-risks analysis was performed using Stata 14.2 for Mac (StataCorp, College Station, TX). All statistical tests were 2-sided, and a $P$ value of $<.05$ was considered statistically significant.

The primary outcomes were long-term survival and freedom from reoperation. Operative mortality was defined as any death regardless of cause occurring within 30 days of surgery or before final discharge from the primary hospitalization (including acute care at other facilities). Variables considered in the analyses included age (years), sex, hypertension, chronic kidney disease, days from onset to diagnosis, days from diagnosis to surgery, days from onset to surgery, acuity (binary), lower limb ischemia, coronary artery bypass grafting, mitral valve surgery, extraanatomic bypass, concomitant Bentall procedure, entry tear location, maximal ascending aortic diameter, early morbidities, and CPB, crossclamping, and selective cerebral perfusion times.

\section{RESULTS \\ Operative Data}

The entry tear was located in the ascending aorta in 55 patients $(51.9 \%)$, the arch in $12(11.3 \%)$, the descending aorta in $9(8.5 \%)$, multiple locations in $25(23.6 \%)$, and unidentified in $5(4.7 \%)$. Among 16 patients who had undergone a previous Bentall procedure, the entry was located in the ascending aorta in 9 , in the arch in 5 , and unidentified in 2. A concomitant aortic root procedure was performed in 82 patients $(77.4 \%)$, including composite graft root replacement in $74(69.8 \%)$, aortic valve replacement in $1(0.9 \%)$, and valve-sparing procedures in 7 
TABLE 1. Preoperative clinical profiles

\begin{tabular}{|c|c|c|c|c|}
\hline Variable & $\begin{array}{c}\text { Total } \\
(n=106)\end{array}$ & $\begin{array}{c}\text { Acute } \\
(n=40)\end{array}$ & $\begin{array}{l}\text { Chronic } \\
(n=66)\end{array}$ & $P$ value \\
\hline Age, $y$, mean $\pm S D$ & $34.5 \pm 9.7$ & $33.2 \pm 9.6$ & $36.0 \pm 9.7$ & .147 \\
\hline Male sex, n (\%) & $80(75.5)$ & $33(82.5)$ & $47(71.2)$ & .190 \\
\hline \multicolumn{5}{|l|}{ Days from onset to diagnosis and surgery, mean $\pm \mathrm{SD}$} \\
\hline Symptom onset to diagnosis* & $15.0(4.0-60.0)$ & $4.0 \pm 3.4$ & $32.5(18.7-316.2)$ & $<.001$ \\
\hline Diagnosis to surgery* & $5.1(1.4-11.1)$ & $1.8 \pm 2.0$ & $10.9 \pm 9.1$ & $<.001$ \\
\hline Symptom onset to surgery* & $22.5(7.4-79.3)$ & $5.8 \pm 3.9$ & $62.6(30.4-318.3)$ & $<.001$ \\
\hline \multicolumn{5}{|l|}{ Comorbidities, n (\%) } \\
\hline Hypertension & $35(33.0)$ & $16(40.0)$ & $19(28.8)$ & .234 \\
\hline Diabetes mellitus & $2(1.9)$ & $1(2.5)$ & $1(1.5)$ & 1.00 \\
\hline Coronary artery disease & $2(1.9)$ & 0 & $2(3.0)$ & .526 \\
\hline Cerebrovascular disease & $1(0.9)$ & 0 & $1(1.5)$ & 1.00 \\
\hline Chronic heart failure & $3(2.8)$ & 0 & $3(4.5)$ & .445 \\
\hline Chronic kidney disease & $2(1.9)$ & $1(2.5)$ & $1(1.5)$ & 1.00 \\
\hline Chronic obstructive pulmonary disease & $1(0.9)$ & 0 & $1(1.5)$ & 1.00 \\
\hline Previous aortic/cardiac procedures, $\mathrm{n}(\%) \dagger$ & $23(21.7)$ & $2(5.0)$ & $21(31.8)$ & .001 \\
\hline Composite graft root replacement & $16(15.1)$ & $1(2.5)$ & $15(22.7)$ & .005 \\
\hline Ascending aortic replacement & $2(1.9)$ & 0 & $2(3.0)$ & .526 \\
\hline Thoracic endovascular aortic repair & $3(2.8)$ & 0 & $3(4.5)$ & .445 \\
\hline Aortic root wrapping & $1(0.9)$ & 0 & $1(1.5)$ & 1.00 \\
\hline Mitral valve repair/replacement & $2(1.9)$ & 0 & $2(3.0)$ & .526 \\
\hline Coronary artery bypass grafting & $1(0.9)$ & 0 & $1(1.5)$ & 1.00 \\
\hline Malperfusion syndrome, $\mathrm{n}(\%) \S$ & $4(3.8)$ & $3(7.5)$ & $1(1.5)$ & .966 \\
\hline Lower limb ischemia & $1(0.9)$ & $1(2.5)$ & 0 & .377 \\
\hline Acute heart failure & $2(1.9)$ & $1(2.5)$ & $1(1.5)$ & 1.00 \\
\hline Acute cardiac tamponade & $1(0.9)$ & $1(2.5)$ & 0 & .377 \\
\hline Maximal ascending aortic size, $\mathrm{mm}$, mean $\pm \mathrm{SD}$ & $60.5 \pm 13.2$ & $57.3 \pm 11.9$ & $62.8 \pm 13.8$ & .067 \\
\hline Aortic regurgitation, $\mathrm{n}(\%)$ & $68(64.1)$ & $28(70.0)$ & $40(60.6)$ & .726 \\
\hline Mild & $41(38.7)$ & $19(47.5)$ & $22(33.3)$ & .147 \\
\hline Moderate & $2(1.9)$ & $1(2.5)$ & $1(1.5)$ & 1.00 \\
\hline Severe & 25 (23.6) & $8(20.0)$ & $17(25.7)$ & .499 \\
\hline
\end{tabular}

$S D$, Standard deviation. *Data with abnormal distributions are expressed by median (interquartile range); comparisons were made with the Mann-Whitney $U$ test. $\dagger$ Refers to the number of patients with a previous history of aortic/cardiac surgery. Specific surgical or endovascular procedures are expressed by the number of cases undertaken. §Refers to the number of patients who had sustained malperfusion preoperatively.

TABLE 2. Operative data

\begin{tabular}{|c|c|c|c|c|}
\hline Variable & $\begin{array}{c}\text { Total } \\
(\mathbf{n}=\mathbf{1 0 6})\end{array}$ & $\begin{array}{c}\text { Acute } \\
(n=40)\end{array}$ & $\begin{array}{l}\text { Chronic } \\
(n=66)\end{array}$ & $P$ value \\
\hline \multicolumn{5}{|l|}{ Procedural time, min, mean $\pm \mathrm{SD}$} \\
\hline Cardiopulmonary bypass & $188.6 \pm 35.3$ & $200.1 \pm 36.7$ & $181.7 \pm 32.8$ & .009 \\
\hline Aortic cross-clamp & $104.8 \pm 25.5$ & $117.9 \pm 27.7$ & $96.9 \pm 20.5$ & $<.001$ \\
\hline Unilateral antegrade cerebral perfusion* & $24.2 \pm 10.1$ & $26.5 \pm 14.3$ & $22.8 \pm 5.9$ & .875 \\
\hline Aortic root procedures, $\mathrm{n}(\%)$ & $82(77.4)$ & $29(72.5)$ & $53(80.3)$ & .350 \\
\hline Valve sparing $\dagger$ & $7(6.6)$ & $2(5.0)$ & $5(7.6)$ & .909 \\
\hline Valve replacement $\ddagger$ & $75(70.7)$ & $27(67.5)$ & $48(72.7)$ & .566 \\
\hline Concomitant procedures, $\mathrm{n}(\%)$ & $14(13.5)$ & $5(12.5)$ & $9(13.6)$ & .292 \\
\hline Extra-anatomic bypass & $8(7.5)$ & $2(5.0)$ & $6(9.1)$ & .694 \\
\hline Coronary artery bypass grafting & $4(3.8)$ & $3(7.5)$ & $1(1.5)$ & .298 \\
\hline Mitral valve operation & $2(1.9)$ & 0 & $2(3.0)$ & .526 \\
\hline
\end{tabular}

$\overline{S D}$, Standard deviation. *Unilateral selective antegrade cerebral perfusion time refers to the interval from initiation of hypothermic circulatory arrest to completion of left carotid anastomosis, after which the brain is perfused bilaterally. Unilateral cerebral perfusion time is longer than hypothermic circulatory arrest time, when lower body perfusion is

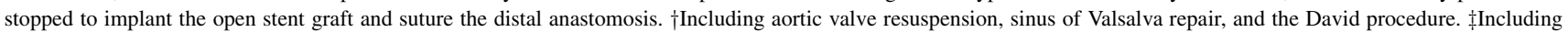
composite graft root replacement (Bentall) in 74 cases and aortic valve replacement in 1 case. 
TABLE 3. Operative mortality and morbidity

\begin{tabular}{|c|c|c|c|c|}
\hline Variable & $\begin{array}{c}\text { Total } \\
(n=106)\end{array}$ & $\begin{array}{c}\text { Acute } \\
(n=40)\end{array}$ & $\begin{array}{l}\text { Chronic } \\
(n=66)\end{array}$ & $P$ value \\
\hline Mortality, n (\%) & $7(6.6)$ & $3(7.5)$ & $4(6.1)$ & 1.000 \\
\hline Multiorgan failure & $6(5.7)$ & $2(5.0)$ & $4(6.1)$ & 1.000 \\
\hline Aortic rupture & $1(0.9)$ & $1(2.5)$ & 0 & .377 \\
\hline Early morbidity, n (\%)* & $17(15.1)$ & $5(12.5)$ & $12(18.2)$ & .126 \\
\hline Stroke & $1(0.9)$ & 0 & $1(1.5)$ & 1.000 \\
\hline Spinal cord injury & $1(0.9)$ & $1(2.5)$ & 0 & .377 \\
\hline Renal failure & $4(3.8)$ & $1(2.5)$ & $3(4.5)$ & 1.000 \\
\hline Postoperative acute heart failure & $4(3.8)$ & $1(2.5)$ & $3(4.5)$ & 1.000 \\
\hline Extremity ischemia & $3(2.8)$ & $2(5.0)$ & $1(3.0)$ & .657 \\
\hline Abdominal aortic dissection & $1(0.9)$ & 0 & $1(1.5)$ & 1.000 \\
\hline Recurrent laryngeal nerve injury & $2(1.9)$ & 0 & $2(3.0)$ & .526 \\
\hline Sternal wound dehiscence & $1(0.9)$ & $1(2.5)$ & 0 & .377 \\
\hline Early reintervention, $\mathrm{n}(\%) \dagger$ & $10(9.4)$ & $6(15.0)$ & $4(6.1)$ & .619 \\
\hline Reexploration for bleeding & $6(5.7)$ & $3(7.5)$ & $3(4.5)$ & .838 \\
\hline Thoracoabdominal aortic replacement & $1(1.9)$ & 0 & $1(1.5)$ & 1.000 \\
\hline Pericardial drainage for effusion & $1(0.9)$ & $1(2.5)$ & 0 & .377 \\
\hline Extra-anatomic bypass & $1(0.9)$ & $1(2.5)$ & 0 & .377 \\
\hline Sternal wound debridement & $1(0.9)$ & $1(2.5)$ & 0 & .377 \\
\hline
\end{tabular}

*Refers to number of patients in whom operative complication occurred. Specific complications are expressed by the number of cases that occurred. $\dagger$ Some patients listed in "reintervention" are overlapped with patients in "early morbidity," except those with "reexploration for bleeding."

$(6.6 \%)$. Concomitant procedures included extra-anatomic bypass in 8 patients $(7.5 \%$; to the femoral artery in 7 and to the abdominal aorta in 1), mitral valve replacement in $2(1.9 \%)$, and coronary artery bypass grafting for dissection-related coronary ischemia in $4(3.8 \%)$.

As shown in Table 2, CPB and cross-clamping times were significantly longer in the acute group compared with the chronic group (CPB: $200 \pm 37$ minutes vs $182 \pm 33$ minutes; $P=.009$; cross-clamping: $118 \pm 28$ minutes vs $97 \pm 20$ minutes; $P<.001$ ), whereas the unilateral selective antegrade cerebral perfusion time did not differ significantly between the 2 groups ( $26 \pm 14$ minutes vs $23 \pm 6$ minutes; $P=.875$ ).

\section{Operative Mortality and Morbidity}

Operative mortality occurred in 7 patients $(6.6 \%)$, including 3 deaths $(7.5 \%)$ in the acute group and 4 deaths $(6.1 \%)$ in the chronic group $(P=1.000)$. The cause of death was multiorgan failure in 6 patients $(5.7 \%$; none associated with preoperative malperfusion syndrome) and descending aortic rupture in 1 patient $(0.9 \%)$.

Early morbidity occurred in 17 patients $(16.0 \%)$, including spinal cord injury and stroke in 1 patient each $(0.9 \%)$, renal failure in 4 patients $(3.8 \%)$, low cardiac output in 4 patients $(3.8 \%)$, extremity ischemia in 3 patients $(2.8 \%)$, and recurrent laryngeal nerve injury in 2 patients $(1.9 \%)$. Reexploration for bleeding was required

TABLE 4. Indication and outcomes of late reoperations

\begin{tabular}{llclll}
\hline Patient & Acute TAAD & Years post-FET & \multicolumn{1}{c}{ Indication } & Reoperation & Survival after reoperation (follow-up) \\
\hline 361 & Yes & 2.3 & Distal aortic aneurysm & TAAA repair & Survival (4.8 y) \\
404 & Yes & 7.7 & Distal aortic aneurysm & TAAA repair & Survival $(0.7$ y) \\
\hline 889 & No & 1.2 & Distal aortic aneurysm & TAAA repair & Survival $(2.0$ y) \\
522 & No & 1.0 & Distal aortic aneurysm & TAAA repair & Survival $(2.8$ y) \\
624 & No & 0.4 & Distal aortic aneurysm & TAAA repair & Survival $(5.3$ y) \\
630 & No & 0.5 & Distal aortic aneurysm & TAAA repair & Survival $(5.8$ y) \\
\hline 754 & No & 5.7 & Distal aortic aneurysm & TAAA repair & Survival $(3.9$ y) \\
1033 & No & 5.4 & Distal aortic aneurysm & TAAA repair & Survival $(3.1$ y) \\
111 & Yes & 0.4 & Distal new entry & TEVAR & Survival $(2.5$ y) \\
350 & Yes & 1.4 & Distal new entry & TEVAR & Survival $(5.2$ y) \\
665 & No & 1.7 & Distal new entry & TEVAR & Death due to aortic rupture (at 4.7 y) \\
12 & No & 0.5 & Coronary anastomotic leakage & Open repair & Death due to acute MI (at $3.1 \mathrm{y})$ \\
\hline
\end{tabular}

TAAD, Type A aortic dissection; FET, frozen elephant trunk; TAAA, thoracoabdominal aortic aneurysm; TEVAR, thoracic endovascular aortic repair; MI, myocardial infarction. 


\section{Late Reoperation}

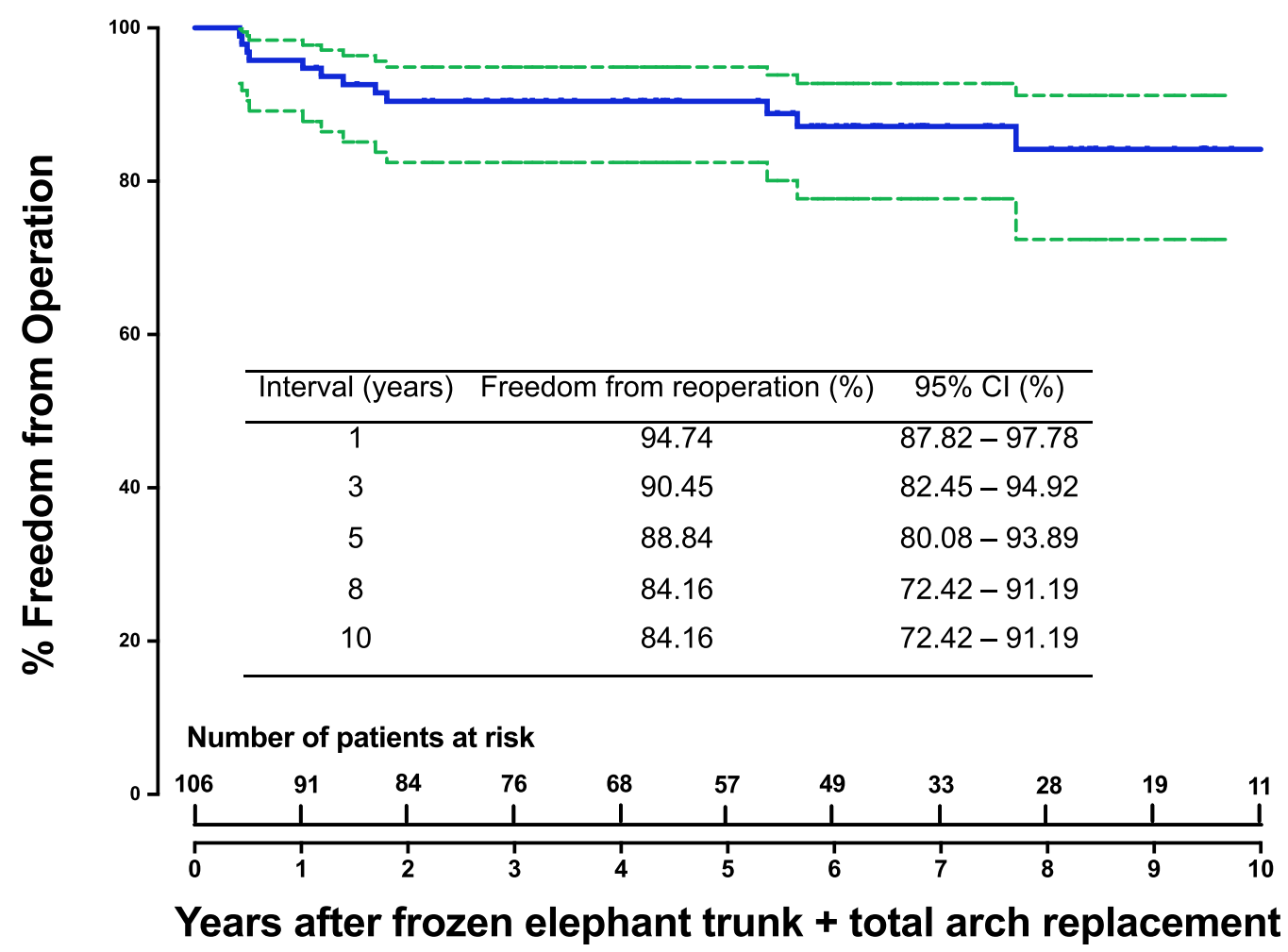

FIGURE 2. Freedom from late reoperation in MFS patients with TAAD following frozen elephant trunk and total arch replacement. CI, Confidence interval.

TABLE 5. Times, causes, and clues of late death

\begin{tabular}{|c|c|c|c|c|c|c|}
\hline Patient & Acute TAAD & Previous aortic repair & Root procedure & Years post-FET & Cause of death & Radiologic clues \\
\hline 35 & Yes & No & No & 1.5 & Unknown & NA \\
\hline 422 & Yes & No & Yes & 4.5 & Unknown & NA \\
\hline 423 & Yes & No & Yes & 9.4 & Distal aortic rupture & Aneurysmal dilation \\
\hline 579 & No & No & Yes & 3.6 & Acute myocardial infarction & NA \\
\hline 599 & No & No & Yes & 3.4 & Distal aortic rupture & Aneurysmal dilation \\
\hline 661 & No & Bentall & No & 6.3 & Distal aortic rupture & Residual dissection \\
\hline 665 & No & No & Yes & 6.4 & Distal aortic rupture & Recurring dissection \\
\hline 711 & No & Bentall & No & 6.0 & Unknown & NA \\
\hline 726 & No & Ascending aortic repair & Yes & 0.3 & Distal aortic rupture & Residual dissection \\
\hline 728 & No & Bentall & No & 6.4 & Unknown & NA \\
\hline 760 & No & No & Yes & 8.0 & Distal aortic rupture & Residual dissection \\
\hline 780 & No & No & No & 8.2 & Unknown & Residual dissection \\
\hline 800 & No & Bentall & No & 6.1 & Unknown & NA \\
\hline 817 & No & No & Yes & 12.0 & Unknown & NA \\
\hline 825 & No & No & Yes & 6.4 & Distal aortic rupture & Recurring dissection \\
\hline 830 & No & No & Yes & 10.6 & Unknown & NA \\
\hline 1037 & No & TEVAR & Yes & 1.1 & Distal aortic rupture & Recurring dissection \\
\hline
\end{tabular}

TAAD, Type A aortic dissection; FET, frozen elephant trunk; NA, not available; TEVAR, thoracic endovascular aortic repair. 


\section{Kaplan-Meier Survival}

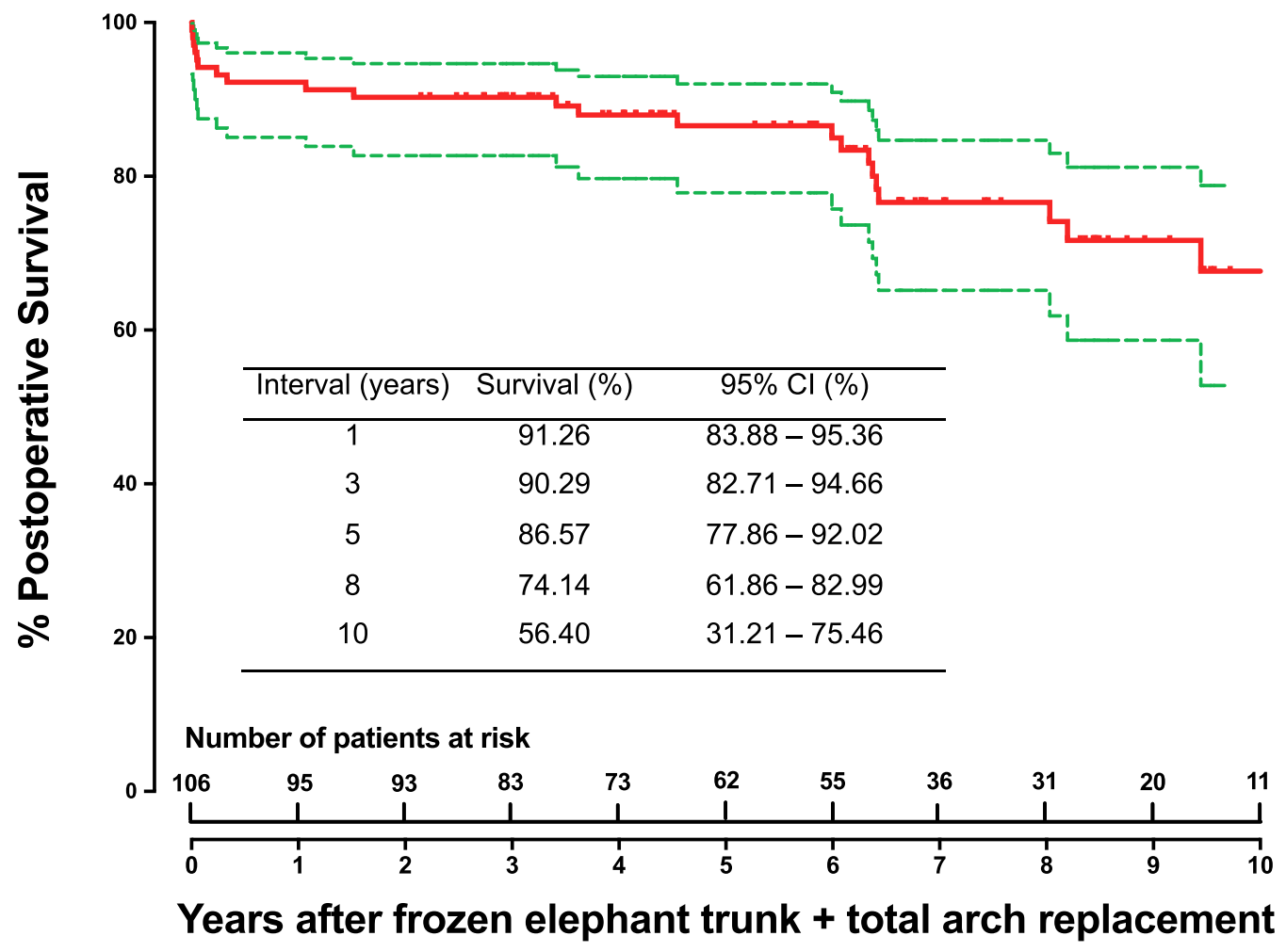

FIGURE 3. Survival of MFS patients with TAAD after frozen elephant trunk and total arch replacement. $C I$, Confidence interval.

in 6 cases $(5.7 \%)$. An acute abdominal aortic dissection occurred in 1 patient $(0.9 \%)$, leading to visceral malperfusion, which necessitated an emergent thoracoabdominal aortic replacement. Unfortunately, the patient succumbed to multiorgan failure at 7 days postsurgery. Other reinterventions included axillary-to-axillary bypass for left arm ischemia, pericardial drainage for effusion, and sternal wound debridement in 1 patient each $(0.9 \%)$. Table 3 presents details on operative complications and mortalities.

\section{Long-Term Outcomes}

Late reoperations and complications. Late reoperations were required in 12 patients (Table 4). Eight patients underwent thoracoabdominal aortic repair for distal aortic aneurysm after FET + TAR; all survived at the latest follow-up $(100 \%)$. TEVAR was performed for distal new entry in 3 patients, at $0.4,1.4$, and 1.7 years, respectively. Following TEVAR, 1 patient died of distal aortic rupture at 4.7 years, and the other 2 patients were alive at 2.5 and 5.3 years. One male patient underwent an open repair of left coronary anastomotic leakage at 0.5 years. He survived the repair but died suddenly of acute myocardial infarction at 3.1 years after the reoperation. Ten of 12 patients were alive at a mean of $3.7 \pm 1.5$ years (range, $0.7-5.8$ years) after the reoperation. No reoperation was required on the aortic root in 8 patients who did not undergo root procedures.

Two patients experienced ischemic stroke due to cerebral infarct, 1 at 2 years and the other at 4 years, which was managed medically. Innominate arterial dissection occurred in 1 patient at 2.4 years. One patient sustained infective endocarditis at 5.4 years with secondary hemiparesis, which was alleviated with medical therapy. A female patient developed mild to moderate claudication attributable to lower extremity ischemia at 1.3 years, which was managed medically.

The freedom from late reoperation was 94.7\% (95\% confidence interval [CI], 87.82\%-97.78\%) at 1 year, $90.5 \%(95 \% \mathrm{CI}, 82.45 \%-94.92 \%)$ at 3 years, $88.8 \%$ $(95 \% \mathrm{CI}, 80.08 \%-93.89 \%)$ at 5 years, and $84.2 \%(95 \%$ CI, $72.42 \%-91.19 \%$ ) at 8 years (Figure 2).

Long-term survival. Of the 99 hospital survivors, 17 died during subsequent follow-up. Eight patients died of distal aortic rupture, from residual dissection in 4 and recurring dissection and aneurysmal dilation in 2 each. One patient died of acute myocardial infarction at 3.6 years (3.1 years after reoperation for coronary anastomotic leakage). The cause of death was unknown in the remaining 8 patients (Table 5).

For the whole cohort, survival was $91.3 \%$ (95\% CI, $83.88 \%-95.36 \%$ ) at 1 year, 90.3\% (95\% CI, 82.71\%$94.66 \%)$ at 3 years, $86.6 \%(95 \%$ CI, $77.86 \%-92.02 \%)$ at 


\section{Competing Risks of Late Death and Reoperation}

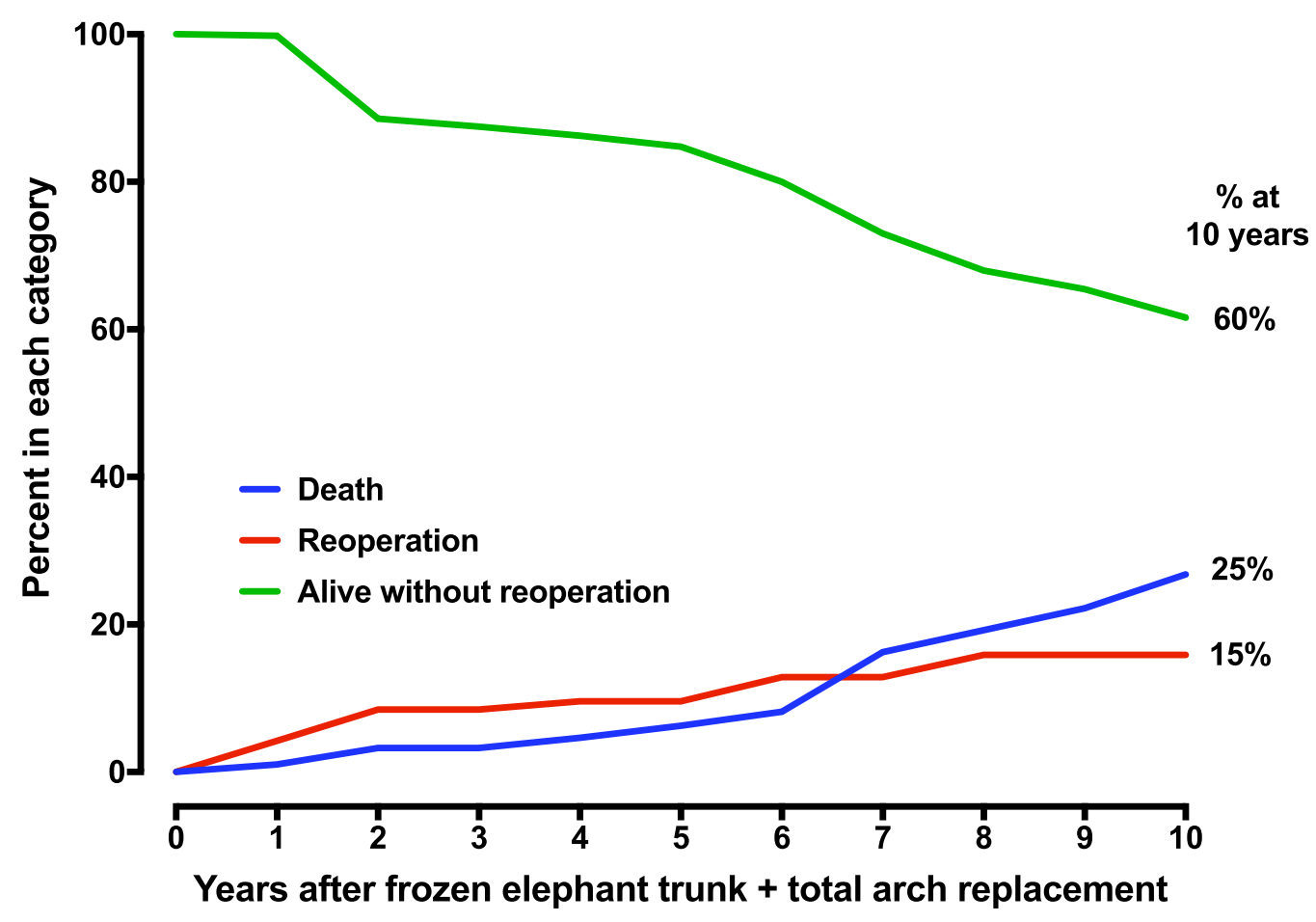

FIGURE 4. Competing risks analysis of death, reoperation, and survival without reoperation.

5 years, and $74.1 \%(95 \% \mathrm{CI}, 61.86 \%-82.99 \%)$ at 8 years (Figure 3).

In competing risks analysis, mortality was $4 \%$ at 5 years, $18 \%$ at 8 years, and $25 \%$ at 10 years; the respective rates of reoperation were $10 \%, 15 \%$, and $15 \%$; and the respective rates of survival without reoperation were $86 \%, 67 \%$, and 60\% (Figure 4).

Impact of acuity, root procedures, and previous aortic/ heart surgery on late outcomes. Acute versus chronic $T A A D$. As shown in Figure 5 and Figure E1, these was no significant difference in freedom from reoperation $(P=.730)$ and survival $(P=.207)$ between patients with acute and chronic TAADs.

Root procedures during TAAD repair. Although patients without root procedures during FET were more likely to have undergone a previous Bentall procedure $(P<.001)$ and repair in the chronic phase $(P=.022)$, with shorter crossclamping times $(P<.001)$, and the early outcomes did not differ significantly between the 2 groups (Table 6), patients with concomitant root procedures had significantly higher survival rates $(P=.047)$ compared with those without root procedures during TAAD repair, which was distinct beyond 6 years (Figure 6). Freedom from reoperation was also higher in patients with root procedures (Figure E2), but without statistical significance $(P=.207)$.
Previous aortic/cardiac surgical procedures. Patients with PHACP were more likely to have preexisting coronary artery disease $(P=.045)$ and to undergo repair in the chronic phase $(P=.001)$, with shorter cross-clamping times during FET $(P=.003)$ (Table 6). Despite comparable early outcomes and freedom from reoperation, survival was significantly lower in patients with $\mathrm{PHACP}$ compared with those without PHACP $(P=.017)$, which was distinct beyond 6 years (Figure 7). Likewise, significantly lower survival was seen in the 16 patients who had undergone a previous Bentall procedure compared with patients without PHACP $(P=.023)$ (Figure E3).

\section{Radiologic Follow-up}

CT scan before discharge showed that the distal end of the FET was inserted into the false lumen in 4 patients $(4.0 \%)$. On follow-up, the true and false lumens and distal aorta remained stable and undilated in 3 patients. Aneurysmal dilation of the distal aorta $(>5 \mathrm{~cm})$ was observed in 1 patient, which was managed with thoracoabdominal aortic replacement. All 4 patients were alive and asymptomatic at the latest follow-up.

Among the 93 patients with follow-up CT scans, complete obliteration of the false lumen across the stented aorta was observed in $80.6 \%(\mathrm{n}=75)$ at 6 months, $86.0 \%$ $(\mathrm{n}=80)$ at 1 year, and $89.2 \%(\mathrm{n}=83)$ at 2 years and beyond, and the false lumen was patent in $19.4 \%$ 


\section{Survival in Acute vs Chronic TAAD}

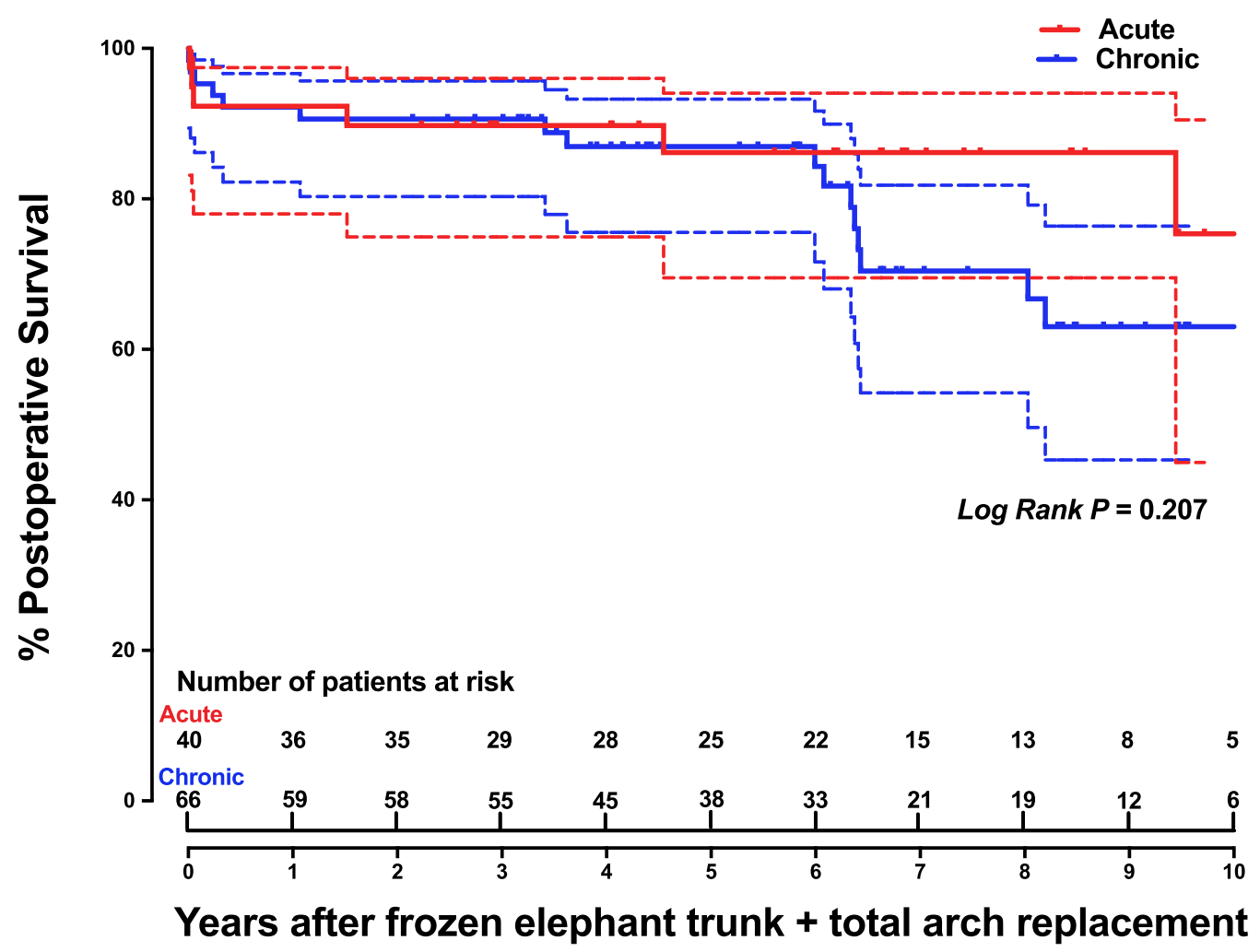

FIGURE 5. Survival of MFS patients with acute versus chronic TAADs after frozen elephant trunk and total arch replacement. TAAD, Type A aortic dissection.

$(\mathrm{n}=18)$ at 6 months, $14.0 \%(\mathrm{n}=13)$ at 1 year, and $10.8 \%$ $(\mathrm{n}=10)$ at 2 years and beyond. Dilatation of the aorta distal to the FET occurred in 3 patients $(3.2 \%)$ at months, in 4 $(4.3 \%)$ at 1 year, in $7(7.5 \%)$ at 2 years, in $9(9.7 \%)$ at 3 years, in $10(10.8 \%)$ at 4 years, in $12(12.9 \%)$ at 5 years, in $17(18.3 \%)$ at 7 years, in $19(20.4 \%)$ at 8 years, in 20 $(21.5 \%)$ at 9 years, and in $23(24.7 \%)$ at 10 years. Eight of the latter 23 patients were managed with thoracoabdominal aortic replacement $(34.8 \%)$. Anastomotic endoleak at the aortic root was detected in 1 patient $(1.1 \%)$ at 6 months, in 1 patient $(1.1 \%)$ at 1 years, and in 6 patients $(6.4 \%)$ at 2 years, and a distal new entry tear was seen in 1 patient $(1.1 \%)$ at 6 months, in 1 patient $(1.1 \%)$ at 1 years, and in 3 patients $(3.2 \%)$ at 2 years.

\section{Risk Factors for Early and Late Adverse Events}

Among the variables assessed in the univariate analyses (Table 7), multivariate analysis identified extra-anatomic bypass as the sole risk factor for early mortality and morbidity (odds ratio [OR], 7.120; 95\% CI, 1.018-49.790; $P=.048$ ), whereas patients with acute TAAD had a significantly lower likelihood of late death than those with chronic TAAD (OR, 0.112; 95\% CI, 0.021-
0.587; $P=.048)$. Risk factors for late reoperation were the duration from diagnosis to surgery (days) (OR, 1.160; 95\% CI, 1.043-1.289; $P=.006)$ and a concomitant Bentall procedure (OR, 12.012; 95\% CI, 1.041-138.606; $P=.046)$.

\section{DISCUSSION}

Although the last 2 decades have seen improved surgical outcomes in patients with MFS, the appropriate or optimal extent of resection during aortic repair remains controversial, $5,14,15$ and the use of the FET technique for TAAD in MFS is still being questioned. ${ }^{25}$ Kazui and associates $^{26}$ recommended concomitant total arch replacement (TAR) for annuloaortic ectasia with DeBakey type I dissection to avoid the risk of reoperation on the aortic arch. In a series of 54 patients with MFS undergoing aortic reoperation, Bachet and colleagues ${ }^{14}$ have concluded that arch replacement is not indicated during elective root replacement, but may be logical for acute TAAD owing to the significant rate of aneurysm dilatation of the aortic arch and the need for subsequent reoperation. A recent study has found that at the time of initial repair for TAAD in MFS, a more aggressive surgical approach seems to be superior to limited repair. ${ }^{4}$ This challenges the commonly 
TABLE 6. Impact of previous aortic/cardiac surgery and concomitant root procedure on early and late outcomes

\begin{tabular}{|c|c|c|c|c|c|c|}
\hline \multirow[b]{2}{*}{ Variables } & \multicolumn{3}{|c|}{ Previous history of aortic/cardiac surgery } & \multicolumn{3}{|c|}{ Concomitant aortic root procedure } \\
\hline & Yes $(n=23)$ & No $(n=83)$ & $P$ value & Yes $(n=82)$ & No $(n=24)$ & $P$ value \\
\hline \multicolumn{7}{|l|}{ Preoperative profile } \\
\hline Age, $y$, mean $\pm S D$ & $35.4 \pm 9.0$ & $34.8 \pm 10.0$ & .794 & $34.8 \pm 9.9$ & $36.0 \pm 9.3$ & .574 \\
\hline Male sex, $\mathrm{n}(\%)$ & $19(82.6)$ & $61(73.5)$ & .369 & $61(74.4)$ & $19(79.2)$ & .632 \\
\hline Acute TAAD, n $(\%)$ & $2(8.7)$ & $38(45.8)$ & .001 & $37(45.1)$ & $3(12.5)$ & .004 \\
\hline \multicolumn{7}{|l|}{ Comorbidities, n (\%) } \\
\hline Hypertension & $8(34.8)$ & $27(32.5)$ & .839 & $25(30.5)$ & $10(41.7)$ & .306 \\
\hline Coronary artery disease & $2(8.7)$ & 0 & .045 & $1(1.2)$ & $1(4.2)$ & .403 \\
\hline Other & $3(13.0)$ & $6(7.2)$ & .376 & $6(7.3)$ & $3(12.5)$ & .700 \\
\hline Previous aortic/cardiac surgery, $\mathrm{n}(\%)$ & $23(100)$ & 0 & $<.001$ & $7(8.5)$ & $16(66.7)$ & $<.001$ \\
\hline Composite graft root replacement & $16(69.6)$ & 0 & $<.001$ & $2(2.4)$ & $14(58.3)$ & $<.001$ \\
\hline Ascending aortic repair and other & $7(30.4)$ & 0 & $<.001$ & $5(6.1)$ & $2(8.3)$ & 1.000 \\
\hline $\begin{array}{l}\text { Maximal ascending aortic diameter, } \\
\mathrm{mm}, \text { mean } \pm \mathrm{SD}\end{array}$ & $60.1 \pm 13.8$ & $60.6 \pm 13.3$ & .912 & $60.7 \pm 12.9$ & $60.6 \pm 16.2$ & .986 \\
\hline \multicolumn{7}{|l|}{ Procedural data } \\
\hline Concomitant aortic root procedure, $\mathrm{n}(\%)$ & $8(34.8)$ & $75(90.4)$ & $<.001$ & $82(100)$ & $24(100)$ & NA \\
\hline $\mathrm{CPB}$ time, min, mean $\pm \mathrm{SD}$ & $198.1 \pm 34.4$ & $186.0 \pm 35.3$ & .146 & $189.2 \pm 36.8$ & $188.8 \pm 29.5$ & .961 \\
\hline Cross-clamp time, min, mean \pm SD & $91.0 \pm 22.3$ & $108.7 \pm 25.1$ & .003 & $110.3 \pm 25.0$ & $86.7 \pm 18.3$ & $<.001$ \\
\hline Cerebral perfusion time, min, mean $\pm \mathrm{SD}$ & $23.2 \pm 6.4$ & $24.5 \pm 10.8$ & .653 & $24.7 \pm 11.0$ & $22.5 \pm 14.3$ & .887 \\
\hline \multicolumn{7}{|l|}{ Early and late outcomes, n (\%) } \\
\hline Operative mortality & $1(4.3)$ & $6(7.2)$ & .986 & $5(6.1)$ & $2(8.3)$ & 1.00 \\
\hline Early morbidities & $3(13.0)$ & $14(16.9)$ & .904 & $16(19.5)$ & $3(12.5)$ & .825 \\
\hline Early reinterventions & 0 & $10(12.0)$ & .178 & $9(11.0)$ & $1(4.2)$ & .544 \\
\hline Late mortality & $6(26.1)$ & $11(13.2)$ & .197 & $11(13.4)$ & $6(25.0)$ & .197 \\
\hline Late reoperations & $2(8.7)$ & $11(13.2)$ & .984 & $11(13.4)$ & $1(4.2)$ & .437 \\
\hline Late complication & $10(43.5)$ & $23(27.7)$ & .148 & $24(29.3)$ & $9(37.5)$ & .444 \\
\hline
\end{tabular}

$S D$, Standard deviation; $T A A D$, type A aortic dissection; $N A$, not applicable; $C P B$, cardiopulmonary bypass.

held philosophy that a more conservative approach is warranted for TAAD repair-that although more extensive surgery is certainly beneficial to avoid reintervention, it carries a greater risk of complications during initial surgical repair. $^{27}$

The present study provides data to address these issues in a large $(n=106)$ series of patients with MFS with TAAD. Despite the considerably improved outcomes of aortic surgery in MFS, there are limited data available on the surgical outcomes for TAAD in MFS. ${ }^{4,5,28,29}$ In a series of 372 patients with MFS, Cameron and coworkers ${ }^{28}$ reported no in-hospital mortality after elective aortic root surgery and a 30-day mortality of only $4.4 \%$ after urgent or emergent ascending aortic repair. The International Registry of Acute Aortic Dissection reported a 23\% perioperative mortality in a cohort of 46 patients age $<40$ years, $50 \%$ of whom had MFS. ${ }^{29}$ In the present series, operative mortality was $6.6 \%$, the incidence of spinal cord injury was $0.9 \%$, and the incidence of stroke was also $0.9 \%$; survival and freedom from reoperation were $74.1 \%$ and $84.2 \%$, respectively, at 8 years. Given the different surgical indications and smaller numbers of patients for other procedures in our experience (Figure 1), it is not possible to compare the results of the more aggressive FET + TAR technique directly with those of the conservative procedures in this study. Nonetheless, in our early experience with type A aortic dissection (including some patients with MFS), we achieved a mortality of $4.7 \%$ with FET + TAR in 148 patients with acute TAAD, which compares favorably to the $6.1 \%$ mortality found in a similar group of 66 patients undergoing hemiarch repair. At mean follow-up of $>42$ months, survival was similar in the 2 groups, but the FET + TAR group had a significantly higher rate of false lumen thrombosis $(94.2 \%$ vs $14.5 \%$; $P<.001)$ and required less surgical reintervention $(0.7 \%$ vs $6.5 \% ; P=.031) .{ }^{30}$ These early and long-term outcomes compare favorably to those of most reported series from high-volume centers ${ }^{4,5,12-15,28}$ and most contemporary series of FET ${ }^{31}$ and TAR. ${ }^{32}$ The results of this study suggest that the extensive FET and TAR approach may be safely performed for TAAD in MFS. With the evolution of currently available devices toward an ideal open stent graft, ${ }^{33}$ the FET technique may add to the cardiovascular surgeon's armamentarium for managing aortic dissection in patients with MFS.

Despite the favorable long-term outcomes in this large series, the use of the FET technique in MFS challenges the current consensus that endovascular stent grafts are contraindicated in patients with connective tissue disorders, ${ }^{19}$ who are generally young with fragile 


\section{Survival with Aortic Root Procedures}

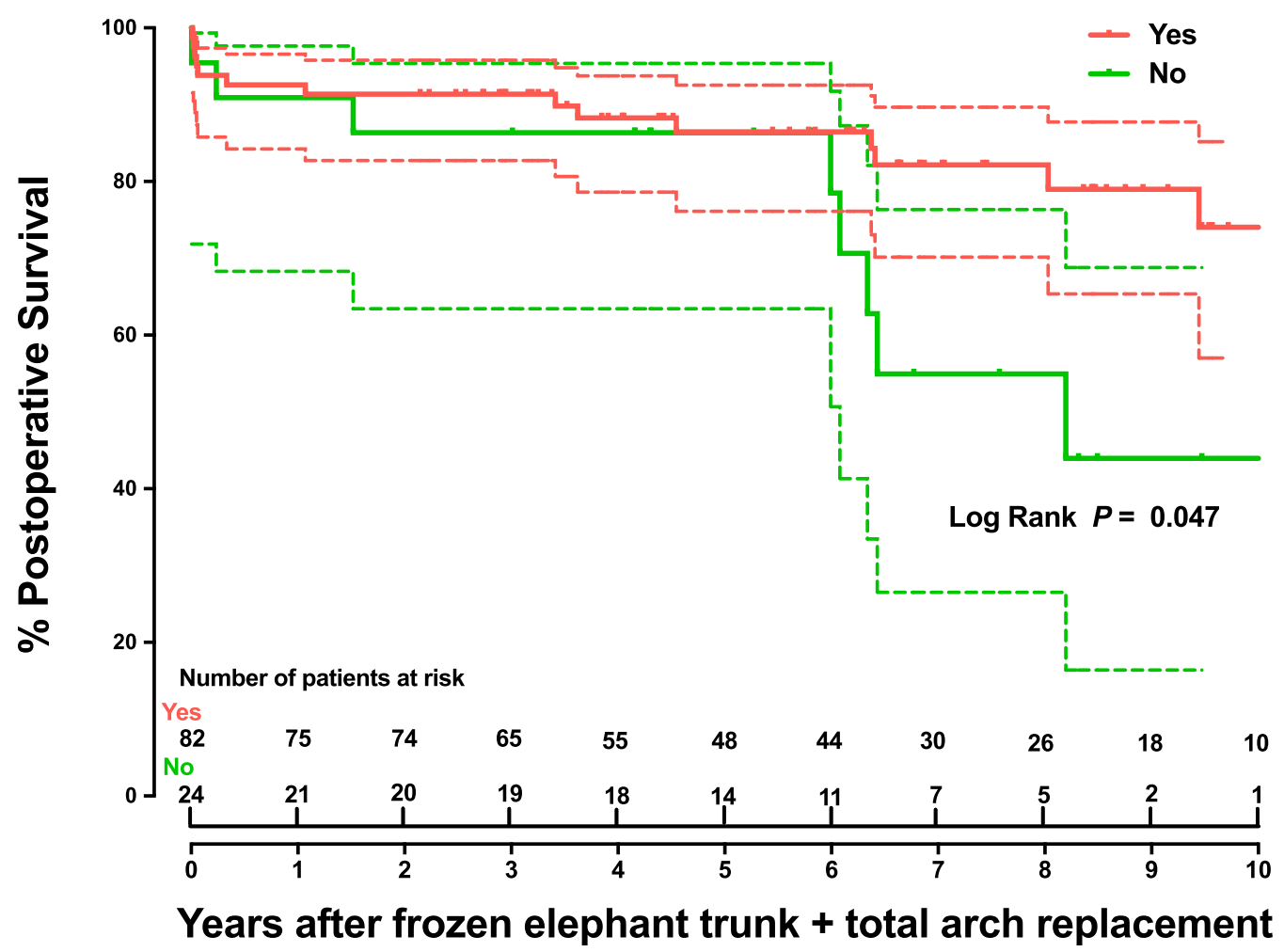

FIGURE 6. Long-term survival was significantly higher in MFS patients with concomitant root procedures during frozen elephant trunk.

tissues and prone to progressive aneurysm formation. ${ }^{34}$ Endovascular stent grafts have been used only as a life-saving bridge to definitive repair or in cases where the stent graft is anchored in surgical grafts proximally and distally. ${ }^{35}$ The literature reports high rates of endoleak and stent-graft migration, and even some unfortunate cases of sudden aortic rupture in patients with MFS treated with endovascular aortic repair. ${ }^{36}$ Moreover, information is limited regarding the impact of persistent radial forces of endovascular stent grafts in the abnormal and weak aortas of patients with such disorders, and the long-term durability of available stent grafts is unknown. The Cronus open stent graft that we use differs from purely endovascular stent grafts with respect to graft material and design. It consists of a regular Dacron vascular tube and interconnected $\mathrm{Z}$-shaped stents made from a Co-Cr-Ni-Mo-Fe alloy. The durability of Dacron is well proven, whereas endovascular stent grafts made from polytetrafluoroethylene or polyester are usually thinner and may be subject to weave deformation by attachment sutures, and thus have limited durability. ${ }^{37}$ In this series, false lumen obliteration across the stented aorta occurred in $89.2 \%$ of patients at mean of 3.5 years, and thoracoabdominal aortic repair for distal aneurysm was required in 8 patients at a mean of $3.0 \pm 1.7$ years, demonstrating the efficacy of the FET in obliterating the false lumen and obviating the need for or delaying distal aortic reinterventions in patients with MFS and TAAD. This is pivotal to the favorable long-term survival and freedom from reoperations, given that a patent false lumen in the dissected aorta of a patient with MFS is a risk factor for late complications, with a predicted mortality of $70 \%$ at 10 years. ${ }^{38}$

Other technical merits of the Cronus graft include the extra centimeter of Dacron sewing cuff at the proximal and distal ends, to which a conventional hand-sewn anastomosis can be performed. Owing to its high flexibility and mechanical durability, it can tolerate the forces of bending, crossclamping, and all other surgical manipulations. ${ }^{33}$ This is helpful in minimizing the risk of proximal endoleak and facilitating manipulations during second-stage repair or reoperations. The descending aorta also may be controlled with a balloon inside the FET in the case of a large false lumen or thrombus. In addition, the distal end of the FET offers an ideal proximal landing zone should TEVAR be required later. In this series, 3 patients with a distal new entry after FET were successfully managed using TEVAR, which suggests that TEVAR may be an alternative approach to distal new entry or residual intimal tears following FET for TAAD in MFS. ${ }^{18}$

This study demonstrates that patients with MFS with acute TAAD are less prone to late death compared with those 


\section{Survival with Previous Aortic/Cardiac Surgery}

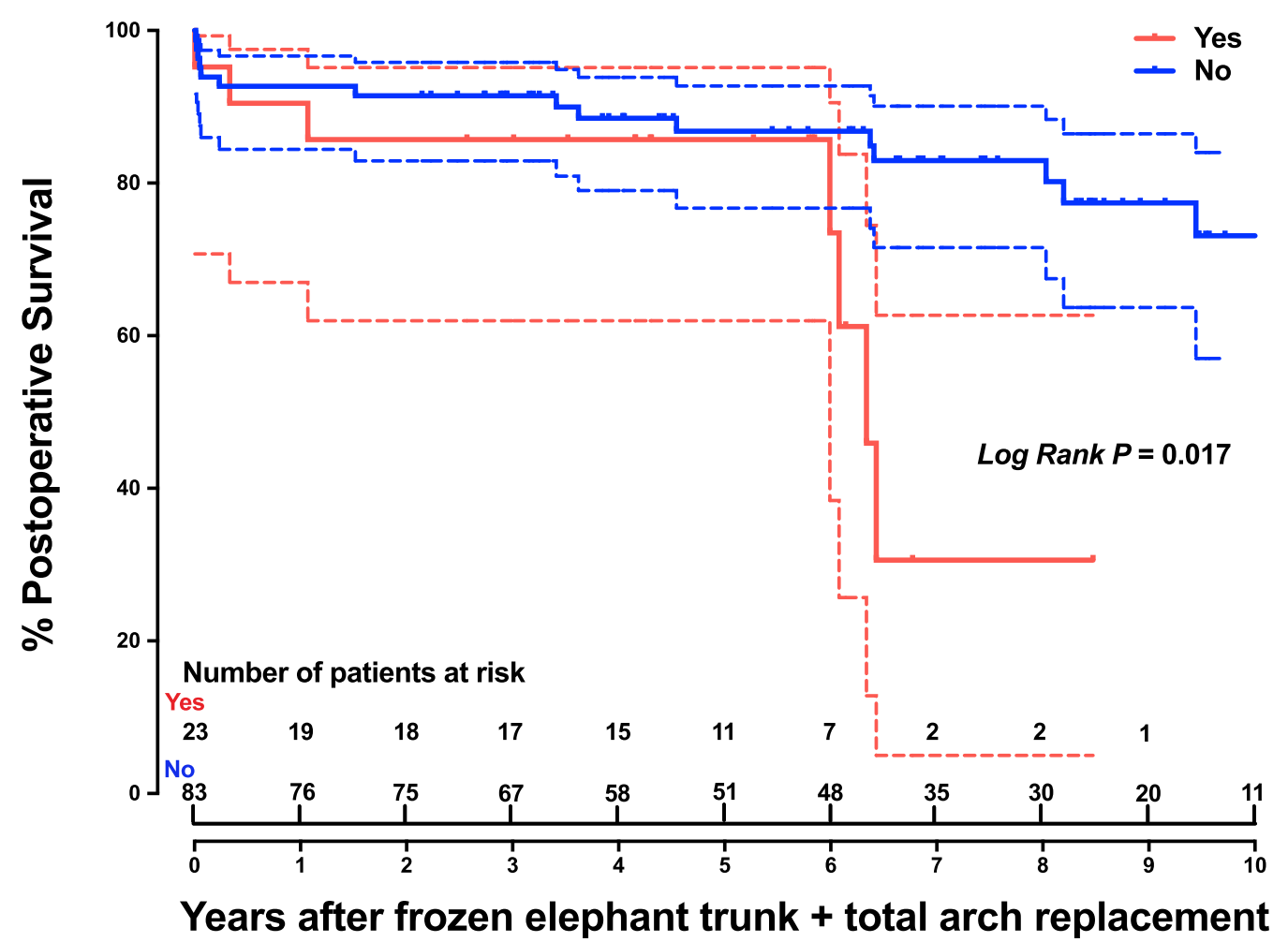

FIGURE 7. Long-term survival was significantly lower in patients with previous aortic/cardiac surgery after frozen elephant trunk and total arch replacement.

with chronic TAAD. This finding appears to contradict the conventional view that acute type A dissection is associated with increased risk of mortality and adverse late outcomes. This paradox may be linked to the differences between

TABLE 7. Risk factors for early and late adverse events

\begin{tabular}{|c|c|c|c|}
\hline Endpoint/risk factor & OR & $\mathbf{9 5} \% \mathrm{CI}$ & $P$ value \\
\hline \multicolumn{4}{|l|}{ Operative mortality and morbidity* } \\
\hline Concomitant extra-anatomic bypass & 7.120 & $1.018-49.790$ & .048 \\
\hline \multicolumn{4}{|l|}{ Late death $\dagger$} \\
\hline Acute dissection ( $\leq 14 \mathrm{~d}$ from onset) & 0.112 & $0.021-0.587$ & .048 \\
\hline \multicolumn{4}{|l|}{ Late reoperation $\ddagger$} \\
\hline Days from diagnosis to operation & 1.160 & $1.043-1.289$ & .006 \\
\hline Concomitant Bentall procedure & 12.012 & $1.041-138.606$ & .046 \\
\hline
\end{tabular}

$O R$, Odds ratio; $C I$, confidence interval. *Variables considered in the analysis included age, sex, hypertension, days from onset to diagnosis, days from diagnosis to surgery and days from onset to surgery, acuity (binary), coronary artery bypass grafting, mitral valve surgery, extra-anatomic bypass, Bentall procedure, entry tear location, maximal ascending aortic diameter, and times of cardiopulmonary bypass, cross-clamping, and selective cerebral perfusion. †Variables considered in the analysis included age, chronic kidney disease, days from onset to surgery, acuity (binary), aortic root procedures, early morbidities, and times of cardiopulmonary bypass, cross-clamping, and selective cerebral perfusion. $\ddagger$ Variables considered in the analysis included age, sex, lower limb ischemia, days from onset to diagnosis, days from diagnosis to surgery, days from diagnosis to surgery, acuity (binary), concomitant Bentall procedure, and times of cardiopulmonary bypass, cross-clamping, and selective cerebral perfusion. patients with acute TAAD and those with chronic TAAD in terms of general conditions and technical difficulties in surgical repair. Patients with chronic TAAD often have a very narrowed true lumen compressed by a large patent false lumen as a result of residual dissections untreated in a previous aortic repair. A considerable proportion of patients with chronic TAAD have already developed a thoracoabdominal aortic aneurysm. These patients are at the more severe end of the disease spectrum and often have a prolonged history and are in poorer general condition. Surgical repair in the chronic setting is more complex and technically demanding; concomitant extra-anatomic bypass may be required in some patients, which may be associated with worse early outcomes and poorer long-term prognosis, contributing to decreased long-term survival. In contrast, the mean interval from symptom onset to surgery was 5.8 days in the patients with acute TAAD, which most likely includes a natural selection process, with the most critical and severe acute patients already expired. This may account for the better long-term survival in patients with acute TAAD.

This study also sheds some light on the issue of extent of aortic resection, ie, limited or extended repair for Marfan patients with TAAD. Even with a significantly longer crossclamping time, a concomitant root procedure was not 
associated with significantly increased rates of operative mortality and complications (Table 6), while achieving better long-term survival in this series possibly by preventing proximal aortic rupture in the short term. This implies that adding a TAR and an FET to aortic root repair may achieve better long-term survival without increasing the risk of early mortality and morbidity in patients with MFS with TAAD. Although this goes against the "less is more" strategy, ${ }^{39}$ the implication is that the more aggressive repair with FET + TAR may be reasonable and superior to limited repair (root, ascending with or without hemiarch) or the staged elephant trunk technique for TAAD in MFS.

Although no surgical procedure has yet been declared the ideal approach to type A dissection in MFS, theoretically the FET procedure may at least eliminate the need for an additional operation on the arch and proximal descending aorta in some patients. This is of particular clinical importance for patients with MFS given the high incidence of reoperations after proximal aortic repair. ${ }^{17,26,40}$

\section{Study Limitations}

This study has some limitations inherent to its retrospective nature. The diagnostic criteria for MFS changed during the course of this study, and the revised Ghent criteria were not applied to earlier patients. Because genetic testing results were not available for most patients, some patients might have been misclassified. Other concerns pertain to the delay in surgery and low rate of preoperative malperfusion, which may reflect a natural selection process during the transfer, with the most severe acute patients weeded out before reaching our center. ${ }^{24}$ Similarly, the extended period from symptom onset to surgery in patients with chronic TAAD may represent a selection bias occurring before referral to our center, whereby the less severe and less complicated cases are more likely to have been selected out and managed by local or peripheral hospitals, while the more severe and complicated cases are more likely to be referred and to reach our institution. The small sample size and number of events affect the stability of our multivariate regression model and statistical power. Because of the high likelihood for significant baseline differences between patient groups with respect to acuity, previous aortic surgery, and root procedure, Kaplan-Meier analyses are unadjusted and are of limited value in estimating survival and reoperation. Although the follow-up rate was high, nearly onehalf of the causes of late deaths were not identified, and longitudinal analysis of repeated CT scans was not performed.

\section{CONCLUSIONS}

In this large series of patients with MFS with TAAD, the FET + TAR technique was associated with a low risk of early mortality and has achieved satisfactory long-term survival and freedom from reoperation. A concomitant Bentall procedure during FET was predictive of better long-term survival and increased risk for late reoperation.
These results argue favorably for the use of the FET + TAR technique for type A aortic dissection in patients with MFS.

\section{Webcast}

You can watch a Webcast of this AATS meeting presentation by going to: http://webcast.aats.org/2016/Video/ Wednesday/05-18-16_Ballroom_I_0834_Ma-800.mp4.

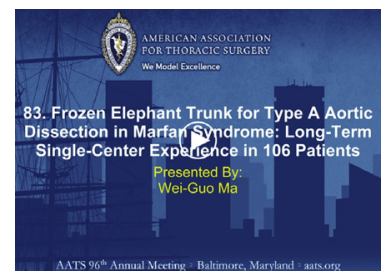

\section{Conflict of Interest Statement}

Authors have nothing to disclose with regard to commercial support.

\section{References}

1. Matt P, Habashi J, Carrel T, Cameron DE, Van Eyk JE, Dietz HC. Recent advances in understanding Marfan syndrome: should we now treat surgical patients with losartan? J Thorac Cardiovasc Surg. 2008;135:389-94.

2. Milewicz DM, Dietz HC, Miller DC. Treatment of aortic disease in patients with Marfan syndrome. Circulation. 2005;111:e150-7.

3. Hiratzka LF, Bakris GL, Beckman JA, Bersin RM, Carr VF, Casey DE Jr, et al. 2010 ACCF/AHA/AATS/ACR/ASA/SCA/SCAI/SIR/STS/SVM guidelines for the diagnosis and management of patients with thoracic aortic disease: a Report of the American College of Cardiology Foundation/American Heart Association Task Force on Practice Guidelines, American Association for Thoracic Surgery, American College of Radiology, American Stroke Association, Society of Cardiovascular Anesthesiologists, Society for Cardiovascular Angiography and Interventions, Society of Interventional Radiology, Society of Thoracic Surgeons, and Society for Vascular Medicine. J Am Coll Cardiol. 2010;55:e27-129.

4. Rylski B, Bavaria JE, Beyersdorf F, Branchetti E, Desai ND, Milewski RK, et al. Type A aortic dissection in Marfan syndrome: extent of initial surgery determines long-term outcome. Circulation. 2014;129:1381-6.

5. Schoenhoff FS, Kadner A, Czerny M, Jungi S, Meszaros K, Schmidli J, et al. Should aortic arch replacement be performed during initial surgery for aortic root aneurysm in patients with Marfan syndrome? Eur J Cardiothorac Surg. 2013;44:346-51; discussion 351.

6. Smith JA, Fann JI, Miller DC, Moore KA, DeAnda A Jr, Mitchell RS, et al. Surgical management of aortic dissection in patients with the Marfan syndrome. Circulation. 1994;90(5 Pt 2):II235-42.

7. Sun LZ, Qi RD, Chang Q, Zhu JM, Liu YM, Yu CT, et al. Surgery for Marfan patients with acute type A dissection using a stented elephant trunk procedure. Ann Thorac Surg. 2008;86:1821-5.

8. Sun LZ, Li M, Zhu JM, Liu YM, Chang Q, Zheng J, et al. Surgery for patients with Marfan syndrome with type A dissection involving the aortic arch using total arch replacement combined with stented elephant trunk implantation: the acute versus the chronic. J Thorac Cardiovasc Surg. 2011;142:e85-91.

9. Uchida N, Katayama A, Kuraoka M, Katayama K, Takahashi S, Takasaki T, et al. Extended aortic repair using frozen elephant trunk technique for Marfan syndrome with acute aortic dissection. Ann Thorac Cardiovasc Surg. 2013;19:279-82.

10. Kim EK, Choi SH, Sung K, Kim WS, Choe YH, Oh JK, et al. Aortic diameter predicts acute type A aortic dissection in patients with Marfan syndrome but not in patients without Marfan syndrome. J Thorac Cardiovasc Surg. 2014 147:1505-10.

11. Coselli JS, Green SY, Price MD, Hash JA, Ouyang Y, Volguina IV, et al. Results of open surgical repair in patients with Marfan syndrome and distal aortic dissection. Ann Thorac Surg. 2016;101:2193-201. 
12. David TE, Armstrong S, Maganti M, Colman J, Bradley TJ. Long-term results of aortic valve-sparing operations in patients with Marfan syndrome. J Thorac Cardiovasc Surg. 2009;138:859-64; discussion 863-4.

13. Price J, Magruder JT, Young A, Grimm JC, Patel ND, Alejo D, et al. Long-term outcomes of aortic root operations for Marfan syndrome: a comparison of Bentall versus aortic valve-sparing procedures. J Thorac Cardiovasc Surg. 2016;151:330-6.

14. Bachet J, Larrazet F, Goudot B, Dreyfus G, Folliguet T, Laborde F, et al. When should the aortic arch be replaced in Marfan patients? Ann Thorac Surg. 2007;83: S774-9; discussion S785-90.

15. Tagusari O, Ogino H, Kobayashi J, Bando K, Minatoya K, Sasaki H, et al. Should the transverse aortic arch be replaced simultaneously with aortic root replacement for annuloaortic ectasia in Marfan syndrome? J Thorac Cardiovasc Surg. 2004;127:1373-80.

16. Girdauskas E, Kuntze T, Borger MA, Falk V, Mohr FW. Distal aortic reinterventions after root surgery in Marfan patients. Ann Thorac Surg. 2008; 86:1815-9.

17. Kari FA, Beyersdorf F, Stephens EH, Peter P, Rylski B, Russe M, et al. Results after thoracic aortic reoperations in Marfan syndrome. Ann Thorac Surg. 2014; 97:1275-80.

18. Botta L, Russo V, La Palombara C, Rosati M, Di Bartolomeo R, Fattori R. Stent graft repair of descending aortic dissection in patients with Marfan syndrome: an effective alternative to open reoperation? J Thorac Cardiovasc Surg. 2009;138: 1108-14.

19. Svensson LG, Kouchoukos NT, Miller DC, Bavaria JE, Coselli JS, Curi MA, et al. Expert consensus document on the treatment of descending thoracic aortic disease using endovascular stent-grafts. Ann Thorac Surg. 2008;85(1 Suppl):S1-41.

20. Ma WG, Zheng J, Zhang W, Sun K, Ziganshin BA, Wang LF, et al. Frozen elephant trunk with total arch replacement for type A aortic dissections: does acuity affect operative mortality? J Thorac Cardiovasc Surg. 2014;148:963-70; discussion 970-2.

21. De Paepe A, Devereux RB, Dietz HC, Hennekam RC, Pyeritz RE. Revised diagnostic criteria for the Marfan syndrome. Am J Med Genet. 1996;62:417-26.

22. Loeys BL, Dietz HC, Braverman AC, Callewaert BL, De Backer J, Devereux RB, et al. The revised Ghent nosology for the Marfan syndrome. J Med Genet. 2010; 47:476-85

23. Ma WG, Zhu JM, Zheng J, Liu YM, Ziganshin BA, Elefteriades JA, et al. Sun's procedure for complex aortic arch repair: total arch replacement using a tetrafurcate graft with stented elephant trunk implantation. Ann Cardiothorac Surg. 2013;2:642-8.

24. Ma WG, Zhang W, Wang LF, Zheng J, Ziganshin BA, Charilaou P, et al. Type A aortic dissection with arch entry tear: surgical experience in 104 patients over a 12-year period. J Thorac Cardiovasc Surg. 2016;151:1581-92.

25. Sundt TM III. The can-should problem. J Thorac Cardiovasc Surg. 2011;142: e91.

26. Kazui T, Yamashita K, Terada H, Washiyama N, Suzuki T, Ohkura K, et al. Late reoperation for proximal aortic and arch complications after previous composite graft replacement in Marfan patients. Ann Thorac Surg. 2003;76:1203-7; discussion 1207-8.

27. Leacche M, Byrne JG. Type A aortic dissection in Marfan syndrome: a case for more aggressive and extensive surgery at the time of the initial surgical operation. Circulation. 2014;129:1373-4.

28. Cameron DE, Alejo DE, Patel ND, Nwakanma LU, Weiss ES, Vricella LA, et al. Aortic root replacement in 372 Marfan patients: evolution of operative repair over 30 years. Ann Thorac Surg. 2009;87:1344-9; discussion 1349-50.

29. Januzzi JL, Marayati F, Mehta RH, Cooper JV, O'Gara PT, Sechtem U, et al. Comparison of aortic dissection in patients with and without Marfan's syndrome (results from the International Registry of Aortic Dissection). Am J Cardiol. 2004;94:400-2.

30. Sun L, Qi R, Zhu J, Liu Y, Zheng J. Total arch replacement combined with stented elephant trunk implantation: a new "standard" therapy for type A dissection involving repair of the aortic arch? Circulation. 2011;123:971-8.

31. Shrestha M, Kaufeld T, Beckmann E, Fleissner F, Umminger J, Abd Alhadi F, et al. Total aortic arch replacement with a novel 4-branched frozen elephant trunk prosthesis: single-center results of the first 100 patients. J Thorac Cardiovasc Surg. 2016;152:148-59.e1.

32. Omura A, Miyahara S, Yamanaka K, Sakamoto T, Matsumori M, Okada K, et al. Early and late outcomes of repaired acute DeBakey type I aortic dissection after graft replacement. J Thorac Cardiovasc Surg. 2016;151:341-8.

33. Ma WG, Zheng J, Sun LZ, Elefteriades JA. Open stented grafts for frozen elephant trunk technique: technical aspects and current outcomes. Aorta (Stamford). 2015;3:122-35.
34. Svensson LG, Eagleton M, Roselli E. Africa's jungle and the arch: of elephants and CHIMPS. J Thorac Cardiovasc Surg. 2016;152:958-9.

35. Ouzounian M, Dagenais F. Chimneys and sandwiches for endovascular arch repair in patients with Marfan syndrome: are we snorkeling in cloudy waters? J Thorac Cardiovasc Surg. 2016;152:1195-6.

36. Ehrlich MP, Nienaber CA, Rousseau H, Beregi JP, Piquet P, Schepens M, et al. Shortterm conversion to open surgery after endovascular stent-grafting of the thoracic aorta: the Talent thoracic registry. J Thorac Cardiovasc Surg. 2008;135:1322-6.

37. Tefera G, Matsumura JS. Aortic stents and stent-grafts. In: Cronenwett JL, Johnston KW, eds. Rutherford's Vascular Surgery. 8th ed. Philadelphia: Saunders; 2014:1431-42.

38. Evangelista A, Salas A, Ribera A, Ferreira-González I, Cuellar H, Pineda V, et al. Long-term outcome of aortic dissection with patent false lumen: predictive role of entry tear size and location. Circulation. 2012;125:3133-41.

39. Sultan I, Szeto WY. Decision making in acute DeBakey I aortic dissection: balancing extensive arch reconstruction versus mortality. J Thorac Cardiovasc Surg. 2016;151:349-50.

40. Geisbuesch S, Schray D, Bischoff MS, Lin HM, Di Luozzo G, Griepp RB Frequency of reoperations in patients with Marfan syndrome. Ann Thorac Surg. 2012;93:1496-501.

Key Words: aorta, thoracic/surgery, aortic dissection, Marfan syndrome, blood vessel prosthesis, frozen elephant trunk, treatment outcome, mortality, Kaplan-Meier estimate, proportional hazards models

\section{Discussion}

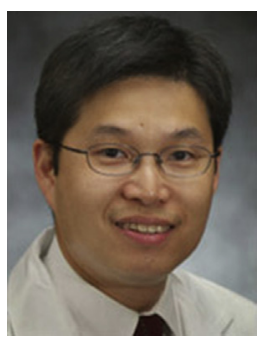

Dr W. Szeto (Philadelphia, Pa). Congratulations, Dr Ma, on a very wellpresented talk. I want to congratulate you on such extraordinary and impressive results. This is obviously a difficult set of patients. Less than $1 \%$ stroke rate, $6.6 \%$ mortality, that is impressive. Just a few questions.

Number one, and you had mentioned this briefly, it is interesting to me that there is this paradox of better long-term survival in the patients with acute dissections as opposed to chronic. As you alluded to in your presentation, the acute dissection patients are longer operations and usually more complex. Why do you think that is the case in your series?

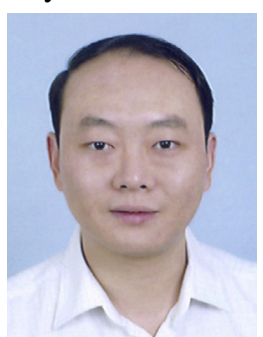

Dr Ma (Beijing, China). Thank you for your high evaluation of our work, $\mathrm{Dr}$ Szeto. Your question brings up an important point. I think the reasons for this paradox lie in 2 aspects. The first is there are a lot of patients with chronic type A dissection who had already received an aortic or a heart operation. These chronic dissection patients tend to have a very narrowed true lumen, which is compressed by an enlarged false lumen as a result of residual dissections untreated during the previous aortic repair. And many of them have a thoracoabdominal aortic aneurysm. These Marfan patients with chronic dissection are at the more 
severe end of the disease spectrum and often have a prolonged history of aortic disease with poorer general condition. So surgical repair in such patients is more complex and technically demanding, and may be associated with worse early outcomes and poorer prognosis. These factors may contribute to the deceased long-term survival in chronic dissection patients.

On the other hand, in patients with acute dissection, the mean duration from symptom onset to surgery was 5.8 days. This delay represents a specific condition of our work. During this interval, some of the most severe patients may have already expired and not reached our center in time for treatment, which likely involves a natural selection process. This may have led to a better survival in some Marfan patients with an acute type A dissection. Thank you.

Dr Szeto. Question 2. As you know, there has been a tremendous amount of controversy regarding the use of endografts in connective tissue disorder patients, Marfan's particularly. You have demonstrated that it is potentially okay to do this. Just to get granular, there were 2 deaths in the series that were of particular concern, and you really did not get into the details in the presentation, but perhaps you can share with the audience. There was 1 early death that resulted from an acute abdominal dissection, and whether the patient had visceral malperfusion ahead of time or not is not clear, but the patient subsequently died from visceral malperfusion. There was a second patient who died on late follow-up who had a late rupture from a TEVAR reintervention.

So, again, the question from me to you and your group is, is the consensus from your group that it is okay to perform endovascular procedures in patients with Marfan's disease or connective tissue disease?

Dr Ma. No, we do not believe that doing endovascular procedures in patients with Marfan syndrome and other connective tissue disorders is completely justified. Even though the open stent graft used in this series differs significantly from endovascular ones with respect to material and design, we are very selective and cautious in the use of the frozen elephant trunk technique in Marfan patients with type A dissection. With regard to the 2 patients whom you mentioned, the first patient sustained preoperative malperfusion manifested as leg ischemia, and died from postoperative abdominal aortic dissection, but autopsy was not performed after his death. It is possible that his death may have been caused by the open stent graft. The second patient underwent TEVAR for a distal new entry after the frozen elephant trunk; he died of aortic rupture caused by the endovascular stent graft.
Despite these concerns, we still speculate that type A dissection in Marfan syndrome is an appropriate indication rather than a contraindication to a frozen elephant trunk. The results of this study show that this procedure is associated with a low risk for early mortality and morbidity and favorable long-term outcomes of survival and freedom from reoperation. However, these complications and deaths have prompted us to redesign this stent graft and modify our surgical techniques to avoid injury to the intima of the aorta distal to the frozen elephant trunk and improve long-term outcomes. A new frozen elephant trunk with a tapered distal end is under clinical investigation now.

Dr Szeto. My third and last question pertains to aortic remodeling. I am interested to hear what your results are. Do you have any results on aortic remodeling in this group as you followed them out and whether there was any difference between the acute group and the chronic group? Thank you again.

Dr Ma. Thank you for bringing up the important issue of aortic remodeling. Based on our incomplete data on imaging follow-up, the false lumen across the stented aorta was completely obliterated in $85 \%$ of patients with acute type A dissection, and in $91.5 \%$ of patients with chronic type A dissection. There was no significant difference in false lumen obliteration between the 2 groups. Thank you.

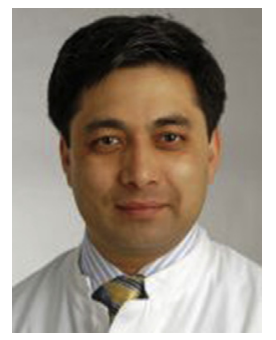

Dr M. Shrestha (Hannover, Germany). Dr Ma, I have 2 questions. The first is what was the duration between time of onset to the time of surgery, because it is not clear from your presentation, and the second is do you do any oversizing of the stent in the descending?

Dr Ma. Thank you for your questions, Dr Shrestha. The mean duration from symptom onset to surgery was $5.8 \pm 3.9$ days in patients with acute dissections, and in patients with chronic dissections, the mean duration from symptom onset to surgery was 280 days and the median was 63 days. In Marfan patients with type A dissection, we are very cautious in oversizing the stent graft; actually, we did not oversize the stent graft in this series of patients.

Dr Shrestha. That means that you already have some sort of natural selection. Some patients are already dead, so you have only more or less stable patients, right?

Dr Ma. Yes, there was some sort of natural selection in this series of patients. Thank you. 


\section{Late Reoperation: Acute vs Chronic}

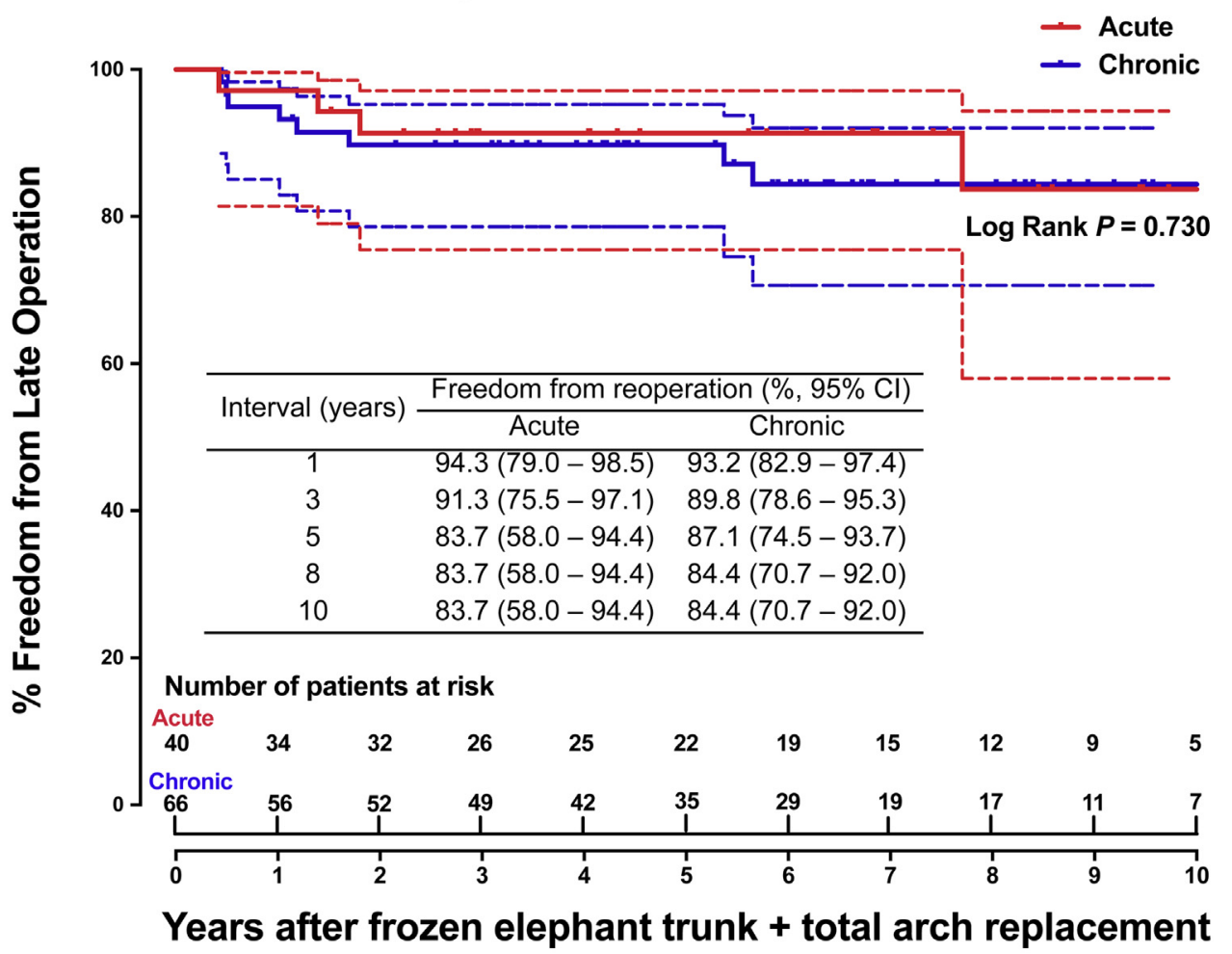

FIGURE E1. Freedom from late reoperation in patients with Marfan syndrome with acute versus chronic type A aortic dissection following frozen elephant trunk and total arch replacement. $C I$, Confidence interval. 


\section{Late Reoperation with Root Procedures}

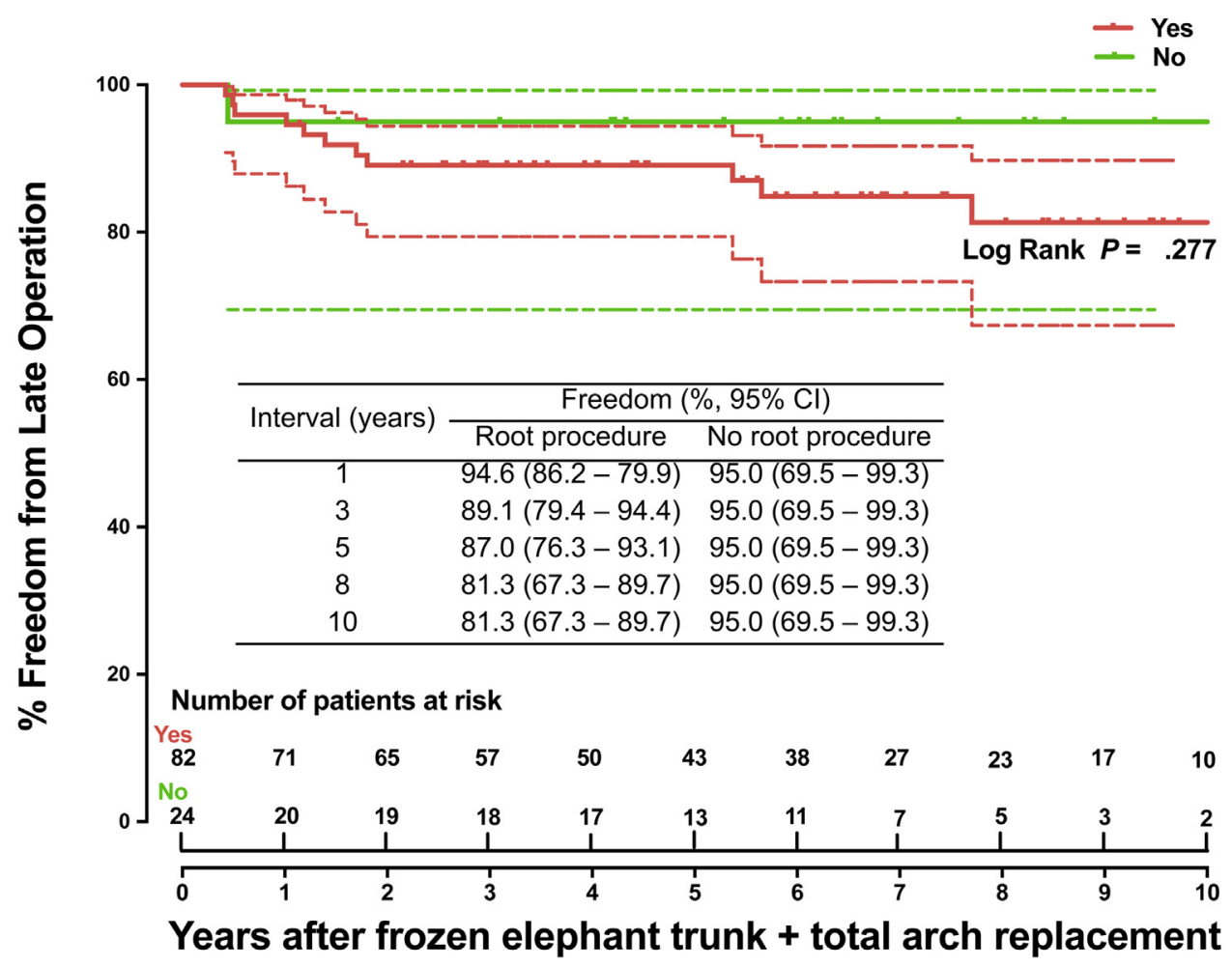

FIGURE E2. Freedom from reoperation was similar in patients with Marfan syndrome with and without root procedures during frozen elephant trunk. $C I$, Confidence interval.

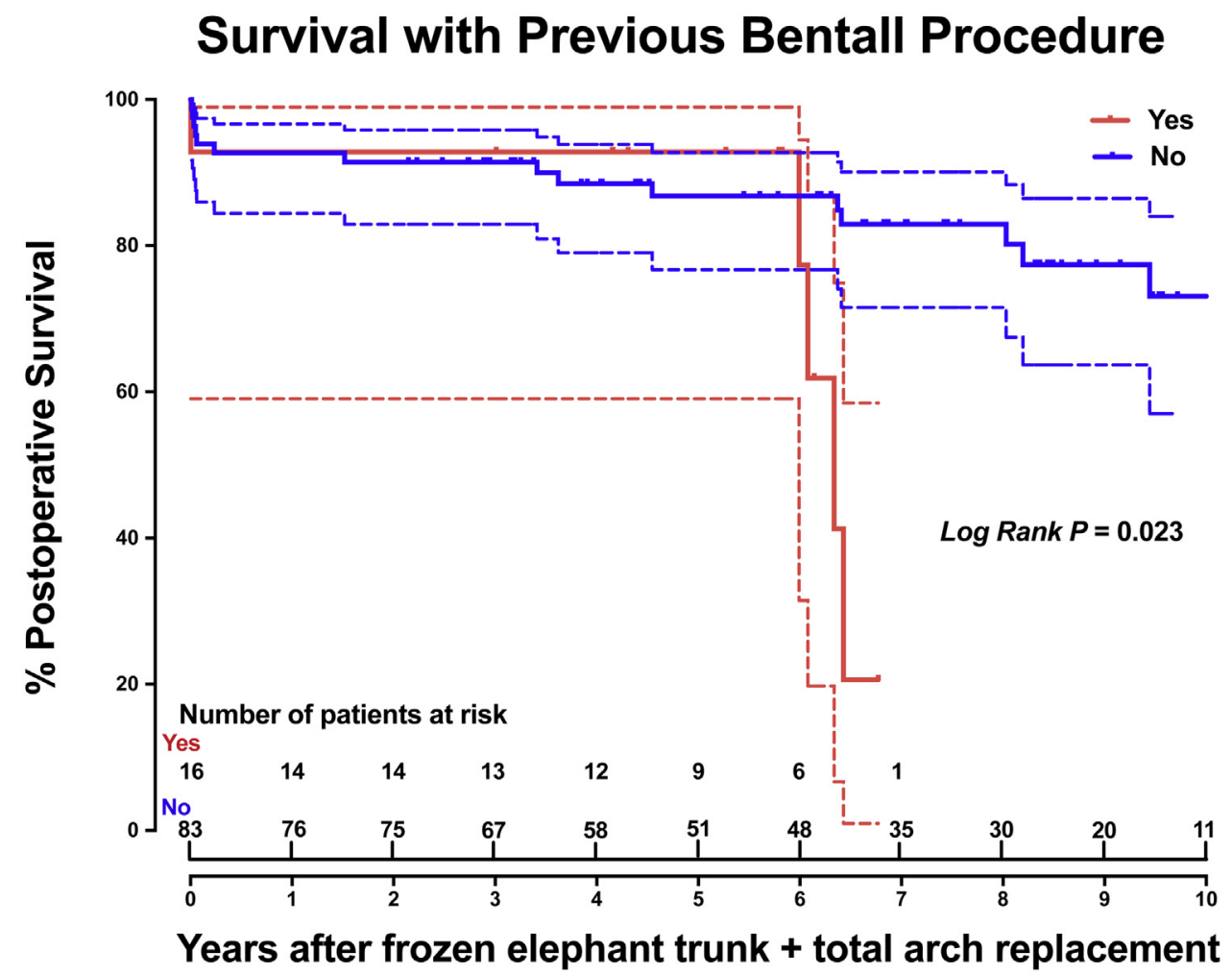

FIGURE E3. Long-term survival was significantly lower in patients with previous Bentall procedure after frozen elephant trunk and total arch replacement. 